\title{
Anatomia do Valor de Empresas
}

\section{Company Value Anatomy}

Vinícius Aversari Martins *

Doutor em Controladoria e Contabilidade pela FEA/USP. Professor do Departamento de Contabilidade da FEA-RP/USP, Ribeirão Preto/SP, Brasil.

Luiz Nelson Guedes de Carvalho

Doutor em Controladoria e Contabilidade pela FEA-USP. Professor do Departamento de Contabilidade e Atuária da FEA/USP, São Paulo/SP, Brasil.

Alexandre Assaf Neto

Doutor em Finanças pela FEA/USP. Professor Titular da FEA-RP/USP, Ribeirão Preto/SP, Brasil.

*Endereço: Rua Ignácio Ferrero, 200, apto. 63, Ribeirão Preto/SP, 14021-560. E-mail: vinicius@usp.br 


\section{RESUMO}

As proposições seminais de Modigliani e Miller iniciaram um campo novo de estudos na moderna teoria de finanças. Com o passar do tempo, suas premissas básicas foram sendo relaxadas, de tal sorte que atualmente são raras as situações em que podem ser aplicadas plenamente, obtendo resultados satisfatórios e consistentes. Por outro lado, pelo fato de esse conjunto simples de proposições ter-se tornado mundialmente conhecido e de fácil aplicação, acabou sendo adotado como receita geral para a avaliação de empresas. Todavia, em situações em que não existe viés de metodologia, os valores resultantes de avaliação de empresa por metodologias tradicionais são herméticos, não possibilitando a análise e administração dos elementos individuais que compõem o valor da firma e do capital próprio. Para se evitar esse tipo de hermetismo na avaliação de empresas, metodologia alternativa de avaliação de empresa é aqui deduzida analiticamente, em que é possível a identificação do valor dos ativos, independentemente da sua forma de financiamento; além disso, são identificados o valor do ganho que a dívida pode proporcionar para o acionista, o benefício fiscal da dívida e a perda de valor do ativo e do benefício fiscal da dívida pelo acréscimo de risco do capital próprio em função de estrutura de capital alavancada. Portanto esse trabalho é teórico.

Palavras-chave: avaliação de empresas; ganho da dívida; estrutura de capital; interações entre investimentos e financiamentos.

\section{Abstract}

The seminal propositions by Modigliani and Miller started a new study area in modern finance theory. Over time, their basic assumptions were relaxed, to the extent that, nowadays, situations in which they can be fully applied, with consistent and satisfactory results, are rare. On the other hand, as this simple set of propositions became known worldwide and was easily applicable, it was adopted as a rule of thumb for general enterprise valuation. However, in situations without methodological bias, the resulting enterprise values obtained by traditional methodologies are abstruse and do not allow for the analysis and management of the individual values that make up the firm and own capital values. In order to avoid this kind of abstruseness in company valuation, this study theoretically deducts an alternative valuation methodology, which permits the identification of assets' value independently of their financing; moreover, we identify the gain on debt value that the debt provides to the shareholders, the debt tax shield and the value loss of assets and tax shield due to the increase in shareholder risk because of the leverage capital structure.

Key words: company valuation; gain on debt; capital structure; assets and financing interactions. 


\section{INTRODUÇÃO}

A avaliação econômica da firma por meio de metodologia que utiliza o custo médio ponderado de capitais (Weighed Average Cost of Capital [WACC]), quando corretamente observadas as condições para sua correta aplicação (Arditti, 1973; Beranek, 1978; Brennan, 1973; Haley \& Schall, 1978; Linke \& Kim, 1974; Mcconnell \& Sandberg, 1975; Miles \& Ezzel, 1980; Miller, 1977, 1986, 1988; Miller \& Modigliani, 1961, 1963; Miller \& Sholes, 1982; Modigliani, 1982, 1983; Modigliani \& Miller, 1958, 1959, 1963, 1969; Myers, 1974, 1977; Nantell \& Carlson, 1975; Reilly \& Wecker, 1973; Ruback, 2002; Vélez-Pareja $\&$ Tham, 2005) resulta no 'correto' valor da firma e, indiretamente, do capital próprio. Entretanto esses valores resultantes são fechados, herméticos, pelo fato de essa metodologia de avaliação de empresas não proporcionar condição para que o valor da firma e do capital próprio sejam decompostos e entendidos em seus diversos componentes. E nesse ponto reside o problema de pesquisa. Myers (1974), ao desenvolver o Adjusted Present Value [APV], demonstra que o valor da firma e do capital próprio podem ser decompostos em tantas partes quanto houver necessidade, em função das interações dos investimentos com a estrutura de capital.

O presente trabalho, de caráter teórico-dedutivo, tem como objetivo resolver as seguintes questões de pesquisa: i) É possível identificar analiticamente a composição do valor da firma e do valor do capital próprio, por ocasião da existência de estrutura de capital alavancada? ii) Caso a resposta da primeira questão seja afirmativa, como fazê-lo na avaliação de empresas?

As deduções teóricas do presente trabalho demonstram as possibilidades de identificação e mensuração dos componentes do valor da firma e do capital próprio decorrentes de interações de ativos operacionais com a estrutura de capital. Dessa discussão teórica é deduzida a metodologia de avaliação de empresa que permite que esses valores sejam identificados e analisados isoladamente. Dá-se a essa metodologia o nome de Anatomia do Valor da Empresa, pois ela permite que os componentes de valor da firma e do capital próprio sejam analisados em função da sua composição analítica, da sua anatomia de valor.

Tal metodologia não utiliza o custo médio ponderado de capital, esquivando-se de todos os seus problemas de natureza conceitual prática. Os custos de capitais relevantes para essa metodologia são os individuais, o do capital próprio sem dívidas, o da dívida e o do capital próprio com dívida. 
Na seção 2 são desenvolvidos os argumentos, analisando-se individualmente os componentes do valor da empresa; na seção 3 é apresentada a dedução de metodologia de avaliação; na seção 4 é apresentada a metodologia completa de avaliação (a anatomia do valor da empresa) e na seção 5 são tecidas considerações finais e propostas novas pesquisas futuras. No apêndice é apresentado um exemplo numérico de aplicação prática da anatomia do valor da empresa.

\section{AnAtomia do Valor da Empresa}

Assume-se como premissa principal desse trabalho teórico que o valor de mercado do capital de terceiros ${ }^{(1)}$ pode não representar o valor justo da dívida para o acionista, por haver custos de oportunidade distintos associados ao fluxo de caixa da dívida. Isso decorre de diferentes alternativas de uso desses fluxos por parte do acionista. É consistente na avaliação de empresas a introdução de um elemento de valor, o Ganho da Dívida [GD], para que o valor total da firma reflita, de forma analítica e não agregada, como ocorre para o uso do $\mathrm{WACC}^{(2)}$, o valor dos ativos operacionais e o valor produzido pela alavancagem financeira, e ambos medidos sob o enfoque do acionista, que é o agente principal da entidade.

$\mathrm{O}$ acionista, por cobrar um prêmio pelo risco financeiro em uma estrutura de capital alavancada, sofre variação em seu custo de capital básico ${ }^{(3)}$. Em termos de utilidade, acaba por não usufruir do potencial total de valor proporcionado pelo investimento, quando financiado integralmente por capital próprio. E é relevante que esse diferencial de valor seja identificado isoladamente no valor das empresas.

Para se entender o todo, deve-se entender cada uma das suas partes, individualmente, e também entender os efeitos decorrentes da interação dessas partes. O que é feito neste trabalho é justamente isso: a partir do entendimento do valor das partes isoladas, parte-se para o entendimento dos valores decorrentes da interação dessas partes, para daí então entender-se o valor do todo. Ao se demonstrar esses componentes todos, entende-se que seja algo análogo ao estudo da 'anatomia' do valor da empresa e do capital próprio, já que o valor total é decompostos em suas partes operacionais, de financiamento e da interação entre elas.

O arcabouço teórico em que o estudo da anatomia se baseia é encontrado, principalmente, no desenvolvimento teórico do Valor Presente Ajustado [APV] feito por Myers (1974), já que ele deduziu que o valor da empresa pode ser composto por diversos fatores. 


\section{Interações entre Ativos e Estrutura de Capital: o Argumento}

O problema de pesquisa reside na mensuração do valor da firma com o uso do WACC, o que corresponde a avaliar os ativos com base no fluxo de caixa livre que eles produzem, descontado por uma taxa que depende não só do risco desses ativos, mas das diferentes composições possíveis de sua forma de financiamento. $\mathrm{O}$ uso do WACC na prática provoca valores distintos de ativos para cada diferente combinação possível dos capitais e seus custos utilizados (Beranek, 1978; Boness, 1964; Bradley, Gregg, \& Kim, 1984; Brennan, 1973; Choi, 1988; Durand, 1989; Ferson \& Locke, 1998; Fernández, 2004, 2006; Gordon, 1989; Haley \& Schall, 1978; Harris \& Raviv, 1991; Henderson, 1979; Kincheloe, 1990; Linke \& Kim, 1974; Löffler, 1998; Masulis, 1983; Mcconnell \& Sandberg, 1975; Miles \& Ezzell, 1980; Nantell \& Carlson, 1975; Paulo, 1992; Reilly \& Wecker, 1973; Robicheck \& Myers, 1966a, 1966b, 1968; Roncaglio \& Zanetti, 2004; Ruback, 2002; Siegel, 1985; Vélez-Pareja \& Tham, 2005; Wang, 1994; Weston, 1989; Wood \& Leitch, 2004; Woods \& Randall, 1989).

Assim, questiona-se a lógica de os ativos mudarem de valor conforme seu financiamento. Vale ressaltar a necessidade de duas avaliações completamente distintas: a dos ativos e a dos passivos, para posteriormente se chegar ao valor do capital próprio. Os ativos devem ser avaliados exclusivamente por um custo que represente o risco que eles carregam, independentemente da forma como são financiados. Já em relação ao passivo, seus efeitos de valor para o capital próprio devem ser considerados à parte, assim como na metodologia de avaliação do Valor Presente Ajustado, o APV (Myers, 1974).

O risco dos acionistas é dado, inicialmente, pelo risco básico dos ativos. Dessa forma, tal risco é aquele medido na presença exclusiva de capital próprio, sendo este igual ao risco dos ativos no qual está aplicado. Isto é, tem-se o custo do capital próprio básico, quando todos os ativos são financiados apenas pelos acionistas, e o risco é dado pelo risco desses ativos.

Os financiadores com capital de terceiros correm o risco da capacidade de geração dos ativos, em termos de valores e de sua distribuição no tempo; porém, como financiam apenas parte do investimento total e têm preferência para receber sua remuneração (juros) e seu principal de volta, sofrem risco menor e, por isso, seu custo é inferior ao do capital próprio.

Na medida em que a empresa adquire dívidas, o custo do capital de terceiros tende a ser alterado (Brigham, Shome, \& Vinson, 1985; Fama \& Jensen, 1983; Freeman \& Hobbes, 1991; Jensen, 1986; Jensen \& Meckling, 1976; Löffler, 1998; Masulis, 1983; Miller, 1988; Myers, 1974, 1977, 1984, 2000, 2001; Wood \& Leitch, 
2004) e, pelo acréscimo do risco nas sobras líquidas com o aumento dos encargos financeiros e dessas dívidas, também pode ser alterado o risco e, conseqüentemente, o custo do capital próprio. Logo, o valor da firma deve conter, de forma diferenciada, os ativos influenciados exclusivamente pelo seu próprio risco, os acionistas com seu risco caracterizado pela presença desses mesmos riscos do ativo mais os relativos à forma de endividamento e o efeito de existirem, como benefício aos acionistas, dívidas com custo inferior ao do capital próprio.

Por isso considera-se como premissa que os ativos devem ser medidos pelo fluxo de caixa livre operacional que produzem, o Fluxo de Caixa Livre dos Ativos (ou Fluxo de Caixa Livre para a Firma ou Empresa), descontado pelo custo do capital próprio necessário a financiá-los integralmente. $\mathrm{O}$ ativo deve ser medido pelo que vale, independentemente da sua forma de financiamento, como se fosse financiado integralmente por capital próprio. Isso resultará, como regra, em um valor para os ativos diferente daquele medido pelo uso do WACC, conforme já apontado anteriormente em referências da literatura.

O diferencial de valor decorrente da interação do ativo com a estrutura de capital (capitais de terceiros e capital próprio) deve ser identificado em separado do valor total da firma. Isso possibilita a administração e a análise dos componentes de valor da firma (a anatomia do valor da firma). Em compensação, cabe aos acionistas um ganho (perda) decorrente dos efeitos da utilização de um capital de terceiros com custo inferior (superior) ao do capital próprio, e esse diferencial representa um acréscimo (diminuição) de valor para os acionistas, o Ganho da Dívida [GD]. Todavia é possível que esses mesmos acionistas estejam sofrendo perda de valor, visto que devem suportar acréscimo de risco pelo acréscimo do endividamento; assim, cada componente desses pode e deve ser mostrado individualmente $^{(4)}$.

Adiante é demonstrado que o valor da empresa fica analiticamente demonstrado pelo ajuste, ao valor dos ativos, da soma algébrica do passivo financeiro, esse ganho na dívida e o diferencial de risco pela presença do endividamento. Como conseqüência direta, esse valor corretamente mensurado é o que se supõe melhor medir a riqueza do capital próprio ${ }^{(5)}$.

\section{Capital de Terceiros: Fluxo de Caixa, Custo de Oportunidade e Valor}

Quando visto como agregado único, o capital de terceiros não possibilita análise detalhada dos seus riscos e taxas de retorno. Partindo-se do princípio de que o capital de terceiros é um portfolio, tem suas principais características expressas em termos de risco e retorno, sendo que o risco agregado depende das correlações 
entre os riscos das dívidas individuais. Cada dívida individual possui riscos distintos, em face das taxas de juros, custos contratuais etc. Em toda a literatura pesquisada, a referência ao valor justo da dívida é baseada sempre no valor de mercado, que reflete o risco que o mercado atribui aos fluxos da dívida. Não foi encontrada literatura sobre precificação de capital de terceiros do ponto de vista do acionista.

Contudo, para o acionista, o fluxo a ser usado como pagamento aos credores é uma diminuição do aproveitamento integral do fluxo de caixa líquido gerado pelos ativos, ou seja, o acionista fica impossibilitado de se aproveitar de todo o fluxo de caixa livre gerado pelos ativos. A existência de capital de terceiros na estrutura de capital de uma empresa implica restrição ao fluxo de caixa livre dos ativos, tendo como conseqüência diminuição do fluxo de caixa livre para o acionista. Assim, a discussão é apoiada pela premissa de que o custo de oportunidade do fluxo da dívida para o acionista difere do custo de oportunidade dos detentores dos capitais de terceiros. Para o acionista, o relevante é o custo de oportunidade do fluxo de caixa livre dos ativos da empresa, uma vez que não poderá aproveitarse dele integralmente.

A primeira implicação, ao se considerar o custo de oportunidade do acionista, sem dívida, como taxa de desconto para o fluxo da dívida, é que o valor justo da dívida para o acionista é diferente do valor justo da dívida para o mercado ou para o credor. A importância em se abordar o valor da dívida sob o ponto de vista do acionista é fundamental na avaliação do capital próprio que, em suma, tem dois componentes principais: o valor gerado pelos ativos e o valor gerado (ou destruído) pela dívida (ou pela alavancagem financeira). E este último decorre, entre outros fatores, da manutenção da dívida ou da sua liquidação, do seu custo (custo para os detentores do capital de terceiros) e do custo de oportunidade do acionista.

\section{Conceito Básico do Ganho da Dívida [GD]: Novo Argumento}

A presença de capitais de terceiros na empresa implica a existência de fluxo de caixa líquido para os donos desses capitais. Sob o ponto de vista da firma, somente ${ }^{(6)}$ haverá saída de caixa para pagamento de juros e principal, se os ativos gerarem fluxos de caixa suficientes para fazer face a esses desembolsos. Para os proprietários da firma (capital próprio), os fluxos de caixa devidos aos donos do capital de terceiros representam restrições aos seus direitos de propriedade sobre os fluxos de caixa livres dos ativos. Como o fluxo de caixa livre dos ativos é distribuído entre mais de um fator de capital, o acionista tem reduzido seu potencial de dividendos, quando comparado ao que poderia obter, caso os ativos fossem (pudessem) ser integralmente financiados por capital próprio ${ }^{(7)}$. Esse último aspecto é relevante para ser analisado. 
Um exemplo inicial para se entender melhor a discussão: supõe-se que do fluxo de caixa livre total dos ativos uma parcela de $\$ 100,00$ seja comprometida a cada período com uma dívida perpétua, ou seja, $\$ 100,00$ de caixa serão subtraídos do fluxo de caixa livre dos ativos para remunerar os detentores de capital de terceiros, cujo custo de oportunidade é de $10 \%$; o valor justo dessa dívida para os donos do capital de terceiros é de $\$ 1.000,00(\$ 100,00 / 0,10)$. Supondo que o custo de oportunidade do capital próprio seja de $12 \%$, a parcela do fluxo de caixa dos ativos no montante de $\$ 100,00$, que vai ser repartido com o capital de terceiros, já que este ajudou a financiar os ativos, poderia ser utilizado para pagamento de dividendos, caso o capital próprio estivesse no lugar do capital de terceiros. Essa parcela do fluxo de caixa dos ativos implicaria valor para os acionistas de $\$ 833,33$ (\$100,00/0,12), se fosse utilizada para pagamento de dividendos. Mas, como o investimento está sendo financiado também com capital de terceiros, tal fluxo de caixa livre dos ativos de $\$ 100,00$ não pode ser utilizado como pagamento de dividendos, pois esse fluxo cabe ao capital de terceiros ${ }^{(8)}$.

Na presença dessa dívida perpétua, a parcela do fluxo de caixa livre dos ativos de $\$ 100,00$ deverá ser utilizado para o pagamento desta, porquanto, em sua presença, os acionistas 'abrem mão' do valor presente do fluxo potencial de dividendos $(\$ 833,33)$ para utilizá-lo nesse pagamento.

O valor justo, para o acionista, desse fluxo utilizado para pagamento de dívidas é, então, de $\$ 833,33$, não de $\$ 1.000,00$ (o valor justo da dívida para os credores). Portanto, o valor relevante da dívida para o sócio é de $\$ 833,33$, o que representa $\$ 166,67$ inferiores ao valor justo da dívida para o dono do capital de terceiros. Nota-se que isso somente é válido sob a premissa de manutenção dessa dívida (ou de fluxo de caixa para o capital de terceiros com as mesmas características).

A situação de o fair value da dívida para o capital próprio ser inferior ao valor justo da dívida para o dono do capital de terceiros somente existe pelo fato de haver um spread positivo entre custo do capital próprio e custo da dívida (custo do capital próprio de $12 \%$, custo da dívida de $10 \%$ e spread positivo de $2 \%$ ). A capacidade do sócio em conseguir financiar parte de seus ativos com capital mais barato que o seu é vantagem econômica: deixa de haver uma estrutura de capital composta exclusivamente por capital próprio para haver uma estrutura de capital alavancada. E, sendo o custo do capital de terceiros (teoricamente) inferior ao do capital próprio, os acionistas acabam ganhando um prêmio em valor proporcional a esse spread, à capacidade do acionista (ou dos administradores da entidade) em conseguir sustentar uma estrutura de capital alavancada com capitais de terceiros mais baratos do 
que o do capital próprio. Utilizando o termo deste trabalho, o prêmio é o denominado Ganho da Dívida [GD].

Caso o custo da dívida seja superior ao custo do capital próprio (spread negativo), o prêmio torna-se um custo adicional. Se por algum motivo o sócio ou os administradores não conseguirem obter capitais de terceiros com custo inferior ao do capital próprio, há perda econômica.

Para a avaliação de empresas, o GD representa a diferença entre o valor presente do fluxo de caixa do capital de terceiros, medido pelo custo de oportunidade do capital de terceiros, e o valor presente desse mesmo fluxo de caixa medido pelo custo de oportunidade do capital próprio. Analiticamente, assumindo-se um fluxo de caixa perpétuo da dívida ${ }^{(9)}$, ainda na ausência de impostos, o Ganho da Dívida é expresso por:

$$
\mathrm{GD}=\mathrm{Fcd} \frac{(\mathrm{ke}-\mathrm{kd})}{(\mathrm{ke} \cdot \mathrm{kd})}
$$

Equação 1,

onde:

GD é o ganho da dívida;

Fcd é o fluxo de caixa perpétuo da dívida;

ke é o custo do capital próprio;

kd é o custo da dívida.

\section{O Ganho da Dívida e o APV: Suporte Conceitual}

O Ganho da Dívida é, conceitualmente, um efeito colateral ${ }^{(10)}$ que se ajusta ao valor fundamental do ativo e que captura os efeitos de valor que possam ser decorrentes da interação entre as formas de financiamento do investimento e das possíveis interações que o investimento possa ter, tanto com ativos já existentes quanto com a estrutura de capital também já existente. Tudo isso já foi preconizado por Myers em 1974 no APV. Na formulação original do APV, o ganho da dívida está incluído no termo $\lambda_{\mathrm{t}}^{\mathrm{F}} \mathrm{Z}_{\mathrm{jt}}$ da equação ${ }^{(11)}$ por ele desenvolvida. Portanto, conceitualmente, a introdução do conceito do ganho da dívida na avaliação da empresa é a consideração explícita de mais um efeito colateral que o capital de terceiros tem, como conseqüência da interação dos investimentos da firma (ou de qualquer projeto) com as estruturas de capital presente e futura. 


\section{A DEDUÇÃo}

\section{Os Modelos Tradicionais de Avaliação da Firma e do Capital Próprio}

Aqui, as seguintes definições ${ }^{(12)}$ são adotadas:

- $\theta_{\mathrm{t}}=$ proporção das dívidas totais sobre capital total no período $\mathrm{t}$;

$\mathrm{ke}_{\mathrm{ut}}=$ custo do capital próprio sem dívidas antes do imposto de renda do período $t$, que representa para esse período o risco básico dos ativos, a taxa de retorno requerida para os ativos em face do seu risco e que independe da estrutura de financiamento;

- $\mathrm{ke}_{\theta \mathrm{t}}=$ custo do capital próprio para o nível de endividamento $\theta_{\mathrm{t}}$;

. $\mathrm{kd}_{\mathrm{nt}}=$ custo da dívida $\mathrm{n}$ no período $\mathrm{t}$;

- $\mathrm{Fca}_{\mathrm{t}}=$ fluxo de caixa livre dos ativos no período $\mathrm{t}$, igual ao fluxo de caixa livre dos ativos operacionais, após os investimentos em capital de giro e investimentos operacionais de longo prazo;

- $\mathrm{Fcd}_{\mathrm{t}}=$ fluxo de caixa líquido para a dívida no período $\mathrm{t}$;

- $\mathrm{Fce}_{\mathrm{t}}=$ fluxo de caixa líquido para o capital próprio no período t;

- $\tau_{\mathrm{at}}=$ alíquota efetiva de imposto de renda sobre o resultado dos ativos no período t;

- $\tau_{\mathrm{dt}}=$ alíquota de imposto de renda para cálculo do benefício fiscal no período $\mathrm{t}$ (geralmente é a alíquota nominal do imposto de renda);

- $\mathrm{w}_{\mathrm{t}}=$ custo médio ponderado de capital do período $\mathrm{t}$.

O valor do capital próprio medido pelo fluxo de caixa livre dos ativos (VEf) é tradicionalmente expresso por:

$$
\operatorname{VEf}_{0}=\sum_{\mathrm{t}=1}^{\infty} \frac{\mathrm{Fca}_{\mathrm{t}}}{\left(1+\mathrm{w}_{\mathrm{t}}\right)^{\mathrm{t}}}-\mathrm{D}_{0}+\mathrm{Af}_{0}
$$

Equação 2, 
onde:

- $\mathrm{VEf}_{0}$ é o valor econômico do capital próprio na data da avaliação (momento 0 ), obtido pela abordagem indireta (diferença entre o valor econômico do ativo e das dívidas);

- $\mathrm{D}_{0}$ é o valor de mercado de todas as dívidas da empresa na data 0 ;

- $\mathrm{Af}_{0}$ é o valor de mercado dos ativos financeiros da empresa na data 0 .

O valor do mesmo capital próprio objeto de avaliação da equação 2 , mas agora expresso pela abordagem direta por meio do fluxo de caixa livre para o acionista, é:

$\mathrm{VEa}_{0}=\sum_{\mathrm{t}=1}^{\infty} \frac{\mathrm{Fce}_{\mathrm{t}}}{\left(1+\mathrm{ke}_{\theta \mathrm{t}}\right)^{\mathrm{t}}}+\mathrm{Af}_{0}$

Equação 3,

onde:

- $\mathrm{VEa}_{0}$ é o valor econômico do capital próprio na data da avaliação (momento o), obtido pela abordagem direta (valor presente dos fluxos de caixa livres para o acionista).

A relação, durante um período de tempo $t$ entre os fluxos de caixa livres para os ativos, para a dívida e para o acionista, é:

$\mathrm{Fce}_{\mathrm{t}}=\mathrm{Fca}_{\mathrm{t}}-\mathrm{Fcd}_{\mathrm{t}}$

Equação 4

Substituindo-se os termos de fluxo de caixa da equação 4 na equação 3 , o valor do capital próprio medido pelo fluxo de caixa livre para o acionista é expresso por:

$$
\mathrm{VEa}_{0}=\sum_{\mathrm{t}=1}^{\infty} \frac{\mathrm{Fca}_{\mathrm{t}}-\mathrm{Fcd}_{\mathrm{t}}}{\left(1+\mathrm{ke}_{\theta \mathrm{t}}\right)^{\mathrm{t}}}+\mathrm{Af}_{0}
$$

Equação 5

Conceitualmente, os valores do capital próprio dados pelas equações 3 e 5 são idênticos, portanto espera-se que $\mathrm{VE}_{\mathrm{f}}-\mathrm{VE}_{\mathrm{a}} \equiv 0$.

\section{O Ganho da Dívida na Avaliação de Empresas}

O conceito do ganho da dívida na perspectiva do acionista representa o valor 
agregado ao capital próprio pelo fato de esse acionista estar alavancando a estrutura de capital com capitais de terceiros, ao invés de utilizar uma estrutura integral de capital próprio. Define-se Ganho da Dívida no momento atual $\left[\mathrm{GD}_{0}\right]$, de uma dívida perpétua (a princípio), como a diferença entre o valor de mercado da dívida e o valor de quanto os acionistas estão economizando de seus próprios fluxos por assumir tal dívida. Analiticamente esse ganho é expresso por:

$$
\mathrm{GD}_{0}=\mathrm{D}_{0}-\frac{\mathrm{Fcd}}{\mathrm{ke}_{\theta \mathrm{t}}}=\mathrm{D}_{0}-\frac{\mathrm{kd} \cdot \mathrm{D}_{0}}{\mathrm{ke}_{\theta \mathrm{t}}}
$$

Equação 6

Ao se considerar a dívida como não perpétua, levando em conta os fluxos de caixa que a representam, em termos de pagamento dos encargos financeiros e amortização do principal, mas ainda sem introduzir os impostos, tem-se que o ganho da dívida é representado por:

$$
\mathrm{GD}_{0}=\mathrm{D}_{0}-\sum_{\mathrm{t}=1}^{\mathrm{n}} \frac{\mathrm{Fcd}_{\mathrm{t}}}{\left(1+\mathrm{ke}_{\theta \mathrm{t}}\right)^{\mathrm{t}}}
$$

Equação 7

A equação 8 implica que, para os acionistas, o valor da dívida corresponde ao fluxo de seu serviço, trazido a valor presente pelo custo do capital próprio dos acionistas. Como esse valor deverá ser inferior, normalmente, ao valor de mercado do passivo financeiro, tem-se aí o valor do ganho pela dívida, o qual é introduzido na avaliação de empresas a seguir.

\section{O Benefício Fiscal}

Ao introduzir-se o imposto de renda no ganho da dívida para o acionista, a taxa de desconto do benefício fiscal é controversa. Assume-se que tal taxa seja igual ao retorno esperado dos ativos, financiados exclusivamente por capital próprio, conforme defendem Kaplan e Ruback (1995), Modigliani (1988), Myers (2001), dentre outros. Assim, define-se o fluxo de caixa do benefício fiscal proporcionado pela dívida no período $\mathrm{t}$ como $\mathrm{Bf}_{\mathrm{t}}$.

O ganho da dívida e o benefício fiscal são, sob a perspectiva do APV (Myers, 1974), efeitos colaterais derivados da interação dos ativos com a estrutura de capital, e são adicionados ao valor do ativo básico (ativo pelo risco básico). Considerando que o APV incorpora também, conceitualmente, o ganho da dívida, o valor da firma é assim expresso:

$$
\mathrm{VF}_{0}=\sum_{\mathrm{t}=1}^{\infty} \frac{\mathrm{Fca}_{\mathrm{t}}}{\left(1+\mathrm{ke}_{\mathrm{ut}}\right)^{\mathrm{t}}}+\mathrm{GD}_{0}+\mathrm{BF}_{0}+\mathrm{AF}_{0}=\mathrm{VA}_{0}+\mathrm{GD}_{0}+\mathrm{BF}_{0}+\mathrm{AF}_{0}
$$

Equação 8, 
onde:

- $\mathrm{VF}_{0}$ é o valor total da firma no momento da avaliação;

- $\mathrm{VA}_{0}$ é o valor, no momento da avaliação, dos ativos geradores de fluxo de caixa livre medidos pelos seus riscos básicos (que independem da estrutura de financiamento), dado por $\sum_{t=1}^{n} \frac{F c a_{t}}{\left(1+k e_{u t}\right)^{t}}$;

- $\mathrm{GD}_{0}$ é o ganho da dívida no momento da avaliação;

- $\mathrm{BF}_{0}$ é o benefício fiscal da dívida no momento da avaliação;

- $\mathrm{AF}_{0}$ é o valor dos ativos financeiros na data da avaliação.

Com o ajuste do ganho da dívida, o valor do capital próprio medido no conceito de fluxo de caixa livre dos ativos é desmembrado da seguinte forma:

$$
\mathrm{VEf}_{0}=\sum_{\mathrm{t}=1}^{\infty} \frac{\mathrm{Fca}_{\mathrm{t}}}{\left(1+\mathrm{ke}_{\mathrm{ut}}\right)^{\mathrm{t}}}+\mathrm{GD}_{0}+\mathrm{BF}_{0}-\mathrm{D}_{0}+\mathrm{AF}_{0}=\mathrm{VA}_{0}+\mathrm{GD}_{0}+\mathrm{BF}_{0}-\mathrm{D}_{0}+\mathrm{AF}_{0}
$$

Equação 9,

onde:

- $\mathrm{VEf}_{0}$ é o valor do capital próprio pela abordagem indireta no momento da avaliação;

- $\mathrm{D}_{0}$ é o valor de mercado das dívidas da empresa no momento da avaliação.

O benefício fiscal pode ser tratado como se fosse uma entrada de caixa na empresa de origem do governo. Quando os juros da dívida são dedutíveis, a empresa obtém uma redução do fluxo de pagamento de imposto de renda sobre o lucro (e contribuição social no Brasil). A geração do imposto a ser pago é vinculada à geração de resultados tributáveis que, via de regra, são decorrentes das atividades operacionais. Quando a empresa obtém o benefício da dedução fiscal sobre os juros da dívida, é como se estivesse pagando o imposto de renda integral sobre os resultados operacionais e recebendo de volta do governo a parcela de imposto já paga, proporcional à aplicação da alíquota de imposto sobre as despesas financeiras ${ }^{(13)}$.

Nesse contexto, nota-se que o benefício fiscal não altera em absolutamente nada o fluxo de caixa da dívida, tanto nos pagamentos de principal quanto nos de juros; esses valores devidos são pagos integralmente. O benefício fiscal dáse pela redução dos impostos operacionais. Em uma situação extrema, caso a empresa não apresente resultado operacional tributável, o benefício fiscal em 
caixa não será obtido naquele ano; ficará postergado para períodos nos quais houver resultados tributáveis.

Contabilmente, dependendo da perspectiva da existência de resultados tributáveis futuros, o benefício pode ou não afetar o resultado contábil. Caso haja perspectiva de geração de resultados tributáveis futuros, o benefício fiscal é registrado como um ativo, e sua realização em caixa (redução de saídas de caixa de imposto de renda) ocorrerá necessariamente não no mesmo período em que foi gerado. Porém, se a perspectiva de geração de resultados futuros for incerta, não haverá o registro contábil do benefício fiscal, não afetando o resultado do período. Por conseguinte, não haverá identificação do fluxo de caixa da dívida líquido do imposto; esse fluxo é considerado integralmente.

O fluxo do benefício fiscal é isolado, tratado como se fosse um ativo individual controlado pela entidade. Partindo desse princípio, os fluxos de caixa de uma empresa com dívidas e com imposto de renda são assim descritos:

$\mathrm{Fca}_{\text {irt }}=\mathrm{Fca}_{\mathrm{t}}-\mathrm{IR}_{\mathrm{op}_{\mathrm{t}}}$

Equação 10,

onde:

- Fca $a_{\text {irt }}$ é o fluxo de caixa livre dos ativos no período t após a consideração dos impostos operacionais;

. Fca $a_{\mathrm{t}}$ é fluxo de caixa livre dos ativos antes dos impostos no período t;

- $\mathrm{IR}_{\mathrm{op}_{\mathrm{t}}}$ é o fluxo de caixa de imposto de renda sobre resultados operacionais do período t.

Não há a aplicação da alíquota de imposto diretamente sobre o fluxo de caixa livre dos ativos pelo fato de o imposto poder ter sua base de cálculo desvinculada desse fluxo. Também não se aplica a alíquota do imposto diretamente sobre o resultado do ativo pelo fato de a legislação nacional permitir adições e/ou exclusões de receitas e/ou despesas operacionais da base de cálculo do imposto. Assim, a alíquota efetiva do imposto pode ser maior, igual ou menor do que a alíquota nominal. Para não haver esse tipo de confusão, isola-se o fluxo de caixa do imposto operacional, denominando-se $\mathbf{I R}_{\mathrm{op}}$.

Quanto ao benefício fiscal da dívida, via de regra, é calculado aplicando-se a alíquota nominal do imposto sobre as despesas financeiras incorridas no período. Dessa forma, o fluxo de caixa do benefício fiscal é denominado $\mathbf{B f}$ e geralmente obtido da seguinte forma: $\mathbf{B f _ { t }}=\mathbf{D F}_{t} \mathbf{x} \mathbf{I R}_{\mathbf{t}}$. 
Definimos nesse ponto $\mathrm{DF}_{\mathrm{t}}$ como sendo o montante de despesas financeiras incorridas no período $t$ que serão dedutíveis da base de cálculo do imposto de renda (e contribuição social no Brasil).

O fluxo de caixa livre para o acionista no período $t$ é assim desmembrado:

$\mathrm{Fce}_{\mathrm{t}}=\mathrm{Fca}_{\mathrm{t}}-\mathrm{IR}_{\mathrm{op}_{\mathrm{t}}}+\mathrm{Bf}_{\mathrm{t}}-\mathrm{Fcd}_{\mathrm{t}}$

Equação 11

A determinação do valor presente do benefício fiscal não é consenso na literatura de finanças (vide, por exemplo, Fernández, 2004; Miles \& Ezzell, 1985). Sob o ponto de vista da firma, o benefício fiscal pode ser dado em função do custo básico dos ativos. Entretanto, para o acionista, o benefício fiscal pode representar um potencial de pagamento de dividendos, ou seja, a diminuição do fluxo de pagamento de impostos pode ser utilizada para pagamento de dividendos. Se for usado para tal, o custo relevante de oportunidade é o custo do capital próprio com dívidas pelo fato de o benefício fiscal somente existe na presença de dívidas. Portanto os dividendos que poderiam ser pagos seriam avaliados pelo custo do capital próprio em estrutura de capital alavancada, e não pelo custo do capital próprio na ausência de dívidas. Dessa forma, é interessante que o fluxo de caixa do benefício fiscal seja avaliado tanto pelo custo do capital próprio em estrutura de capital alavancada quanto pelo custo do capital próprio em estrutura desalavancada. Essa medida dá uma noção de quanto de valor o acionista não consegue ter de utilidade por estar usando dívidas no financiamento dos ativos.

Analiticamente, o benefício fiscal aproveitado pelo o acionista é:

$$
\mathrm{VBf}_{\mathrm{o}}=\sum_{\mathrm{t}=1}^{\infty} \frac{\left(\mathrm{Bf}_{\mathrm{t}}\right)}{\left(1+\mathrm{ke}_{\mathrm{ut}}\right)^{\mathrm{t}}}-\sum_{\mathrm{t}=1}^{\infty}\left(\mathrm{Bf}_{\mathrm{t}}\right) \frac{\left(\mathrm{ke}_{\mathrm{ut}}-\mathrm{ke}_{\theta \mathrm{t}}\right)}{\left(1+\mathrm{ke}_{\mathrm{ut}}\right)^{\mathrm{t}}\left(1+\mathrm{ke}_{\theta t}\right)^{\mathrm{t}}}
$$
onde:

- $\operatorname{VBf}_{0}$ é o valor do benefício fiscal para o acionista na data da avaliação;

. $\mathrm{Bf}_{\mathrm{t}}$ é o fluxo de caixa do benefício fiscal;

$\mathrm{ke}_{\mathrm{ut}}$ e $\mathrm{ke}_{\theta \mathrm{t}}$ são os custos do capital próprio sem e com dívidas.

O termo da direita da equação 12 representa a diferença entre os valores do benefício fiscal mensurado pelo custo do capital próprio, sem dívidas, e pelo custo do capital próprio com dívida. Essa parte da equação representa o quanto de valor o acionista não aproveita do benefício fiscal por possuir dívidas financiando os ativos. O termo é substituído por $\Delta \mathrm{BF}_{0}$. Assim sendo, a equação representando o valor do benefício fiscal é reescrita: 
$\mathrm{VBf}_{\mathrm{o}}=\sum_{\mathrm{t}=1}^{\mathrm{n}} \frac{\left(\mathrm{Bf}_{\mathrm{t}}\right)}{\left(1+\mathrm{ke}_{\mathrm{ut}}\right)^{\mathrm{t}}}-\Delta \mathrm{VBF}_{0}$

Equação 13

\section{O Risco Financeiro Arcado pelo Capital Próprio e seus Efeitos sobre o Ativo e o Benefício Fiscal}

Considerando que o capital próprio exige prêmio de risco para a estrutura de capital alavancada, conforme a segunda proposição de Modigliani e Miller (1958, 1959, 1963, 1969; Miller, 1977, 1986, 1988, 1991), a sua avaliação deve levar em conta esse aspecto. $\mathrm{O}$ aumento do endividamento gera aumento de retorno esperado para o capital próprio, mas representado por aumento do custo desse mesmo capital próprio.

O valor do ativo operacional percebido pelos acionistas é função do custo do capital próprio. $\mathrm{Na}$ ausência do capital de terceiros, há a igualdade entre o retorno mínimo esperado do ativo e o custo do capital próprio. Com a introdução do capital de terceiros, o custo do capital próprio eleva-se, ficando superior ao risco básico do ativo. E esse diferencial de custo do capital próprio explica a diminuição de aproveitamento do valor do ativo por parte dos acionistas, sendo, portanto, esse valor (em estrutura de capital alavancada) percebido pelos acionistas inferior ao valor do ativo na ausência de dívidas.

Os acionistas, ao invés de se aproveitarem do valor integral do ativo na ausência de dívidas, incorrem em uma perda econômica de valor por haver aumento do custo do capital próprio. E esse diferencial de valor pode e é muito relevante de ser identificado isoladamente, à parte do valor do ativo na ausência de dívidas.

A firma como um todo inclui esses dois componentes: o ativo na ausência de dívidas e a perda de valor do ativo por parte dos acionistas. Esse ponto é fundamental neste trabalho, pois representa a conclusão parcial das questões de pesquisa.

Sendo assim, a formulação do valor de mercado da firma sob a perspectiva do capital próprio, dada pelo fluxo de caixa livre para a empresa é:

$$
\begin{aligned}
& \mathrm{VF}_{0}=\sum_{\mathrm{t}=1}^{\infty} \frac{\mathrm{Fca}_{\mathrm{t}}}{\left(1+\mathrm{ke}_{\mathrm{ut}}\right)^{\mathrm{t}}}+\mathrm{GD}_{0}+\mathrm{BF}_{0}+\Delta \mathrm{VA}_{0}+\mathrm{AF}_{0}= \\
& \mathrm{VA}_{0}+\mathrm{GD}_{0}+\mathrm{BF}_{0}+\Delta \mathrm{VA}_{0}+\mathrm{AF}_{0} \\
& \text { onde } \Delta \mathrm{VA}_{0}=-\sum_{\mathrm{t}=1}^{\infty} \mathrm{Fca}_{\mathrm{t}}\left(\frac{\left(\mathrm{ke}_{\mathrm{ut}}-\mathrm{ke}_{\theta \mathrm{t}}\right)}{\left(1+\mathrm{ke}_{\mathrm{ut}}\right)^{\mathrm{t}}\left(1+\mathrm{ke}_{\theta \mathrm{t}}\right)^{\mathrm{t}}}\right)
\end{aligned}
$$


sendo que

$\Delta \mathrm{VA}_{0}$ é a variação de percepção de valor do ativo pelo aumento do risco financeiro no custo do capital próprio no momento da avaliação;

- $\mathrm{ke}_{\mathrm{ut}}$ é o custo do capital próprio na ausência de dívidas, ou o risco básico do ativo;

- $\mathrm{ke}_{\theta \mathrm{t}}$ é o custo do capital próprio na presença de dívidas.

A equação 15 representa a diferença de valor dos ativos, quando mensurados pelo custo do capital próprio sem dívidas e pelo custo do capital próprio com dívidas. Representa de quanto valor dos ativos o acionista não se beneficia, por ter tido seu custo de capital aumentado por causa da estrutura de capital alavancada.

Da forma como a dedução está sendo feita, pode-se verificar que está havendo uma dissecação anatômica do valor da empresa e do capital próprio, conforme o objetivo do trabalho.

\section{A Racionalidade do Ganho da Dívida e do Valor do Ativo para o Capital Próprio}

O valor do capital próprio, quando calculado em função do fluxo de caixa livre para o acionista, dado por $\mathrm{VEa}=\sum_{\mathrm{t}=1}^{\infty} \frac{\mathrm{Fce}_{\mathrm{t}}}{\left(1+\mathrm{ke}_{\theta t}\right)}$, é equivalente a $\mathrm{VEa}=\sum_{\mathrm{t}=1}^{\infty} \frac{\left(\mathrm{Fca}_{\mathrm{t}}-\mathrm{Fcd}_{\mathrm{t}}\right)}{\left(1+\mathrm{ke}_{\theta \mathrm{t}}\right)}$ já que o fluxo de caixa livre para o acionista é dado pela diferença entre o fluxo de caixa livre dos ativos e o fluxo de caixa líquido da dívida. Fazendo o desmembramento dos dois itens, ativos e dívidas, o valor do capital próprio é dado por $\mathrm{VEa}=\sum_{\mathrm{t}=1}^{\infty} \frac{\left(\mathrm{Fca}_{\mathrm{t}}\right)}{\left(1+\mathrm{ke}_{\theta \mathrm{t}}\right)}-\sum_{\mathrm{t}=1}^{\infty} \frac{\left(\mathrm{Fcd}_{\mathrm{t}}\right)}{\left(1+\mathrm{ke}_{\theta \mathrm{t}}\right)}$.

Esses dois componentes representam o valor do ativo e da dívida percebidos pelo acionista. Todavia, dessa forma, o valor do capital próprio resultante é 'fechado', não revelando o valor de mercado do ativo, independentemente da sua forma de financiamento, assim como o valor de mercado da dívida. A introdução do ganho da dívida e do diferencial de valor do ativo (e do benefício fiscal), na avaliação do capital próprio, permite que esses componentes todos sejam identificados isoladamente. A equivalência entre o 
valor do ativo percebido pelo acionista $\left(\mathrm{VA}_{0 \text { acionista }}\right), \sum_{\mathrm{t}=1}^{\mathrm{n}} \frac{\left(\mathrm{Fca}_{\mathrm{t}}\right)}{\left(1+\mathrm{ke}_{\theta \mathrm{t}}\right)}$, e o valor de mercado do ativo sem dívidas é:

$$
\begin{aligned}
& \mathrm{VA}_{0 \text { acionista }}=\sum_{\mathrm{t}=1}^{\infty} \frac{\mathrm{Fca}_{\mathrm{t}}}{\left(1+\mathrm{ke}_{\mathrm{ut}}\right)^{\mathrm{t}}}-\Delta \mathrm{VA}_{\mathrm{o}}=\sum_{\mathrm{t}=1}^{\infty} \frac{\mathrm{Fca}_{\mathrm{t}}}{\left(1+\mathrm{ke}_{\theta \mathrm{t}}\right)^{\mathrm{t}}}, \text { já que } \\
& \Delta \mathrm{VA}_{\mathrm{o}}=\sum_{\mathrm{t}=1}^{\infty}\left(\frac{\mathrm{Fca}_{\mathrm{t}}}{\left(1+\mathrm{ke}_{\mathrm{ut}}\right)^{\mathrm{t}}}-\frac{\mathrm{Fca}_{\mathrm{t}}}{\left(1+\mathrm{ke}_{\theta \mathrm{t}}\right)^{\mathrm{t}}}\right)=\sum_{\mathrm{t}=1}^{\infty}\left(\mathrm{Fca}_{\mathrm{t}} \cdot \frac{\left(\mathrm{ke}_{\mathrm{ut}}-\mathrm{ke}_{\theta \mathrm{t}}\right)}{\left(1+\mathrm{ke}_{\mathrm{ut}}\right)^{\mathrm{t}} \cdot\left(1+\mathrm{ke}_{\theta \mathrm{t}}\right)^{\mathrm{t}}}\right) .
\end{aligned}
$$

A equivalência entre o valor da dívida para o acionista $\left(\mathrm{D}_{\text {0acionista }}\right), \sum_{\mathrm{t}=1}^{\infty} \frac{\left(\mathrm{Fcd}_{\mathrm{t}}\right)}{\left(1+\mathrm{ke}_{\theta \mathrm{t}}\right)}$, e o valor de mercado da dívida é: $\mathrm{D}_{0 \text { acionista }}=\sum_{\mathrm{t}=1}^{\infty} \frac{\mathrm{Fcd}_{\mathrm{t}}}{\left(1+\mathrm{kd}_{\mathrm{t}}\right)^{\mathrm{t}}}+\mathrm{GD}_{\mathrm{o}}=\sum_{\mathrm{t}=1}^{\infty} \frac{\mathrm{Fcd}_{\mathrm{t}}}{\left(1+\mathrm{ke}_{\theta \mathrm{t}}\right)^{\mathrm{t}}}$, já que $\mathrm{GD}_{\mathrm{o}}=\sum_{\mathrm{t}=1}^{\infty}\left(\frac{\mathrm{Fcd}_{\mathrm{t}}}{\left(1+\mathrm{ke}_{\theta \mathrm{t}}\right)^{\mathrm{t}}}-\frac{\mathrm{Fcd}_{\mathrm{t}}}{\left(1+\mathrm{kd}_{\mathrm{t}}\right)^{\mathrm{t}}}\right)=\sum_{\mathrm{t}=1}^{\infty}\left(\mathrm{Fcd}_{\mathrm{t}} \cdot \frac{\left(\mathrm{ke}_{\theta \mathrm{t}}-\mathrm{kd}_{\mathrm{t}}\right)}{\left(1+\mathrm{kd}_{\mathrm{t}}\right)^{\mathrm{t}} \cdot\left(1+\mathrm{ke}_{\theta \mathrm{t}}\right)^{\mathrm{t}}}\right)$.

Dessa forma, a avaliação do capital próprio pelo fluxo de caixa livre para o acionista é equivalente a

$$
\begin{aligned}
& \mathrm{VEa}=\sum_{\mathrm{t}=1}^{\infty} \frac{\mathrm{Fce}_{\mathrm{t}}}{\left(1+\mathrm{ke}_{\theta t}\right)^{\mathrm{t}}}=\sum_{\mathrm{t}=1}^{\infty} \frac{\left(\mathrm{Fca}_{\mathrm{t}}-\mathrm{Fcd}_{\mathrm{t}}\right)}{\left(1+\mathrm{ke}_{\theta t}\right)^{\mathrm{t}}}= \\
& =\sum_{\mathrm{t}=1}^{\infty} \frac{\mathrm{Fca}_{\mathrm{t}}}{\left(1+\mathrm{ke}_{\mathrm{ut}}\right)^{\mathrm{t}}}+\sum_{\mathrm{t}=1}^{\infty}\left(F c \mathrm{~F}_{\mathrm{t}} \cdot \frac{\left(\mathrm{ke}_{\mathrm{ut}}-\mathrm{ke}_{\theta t}\right)}{\left(1+\mathrm{ke}_{\mathrm{ut}}\right)^{\mathrm{t}} \cdot\left(1+\mathrm{ke}_{\theta t}\right)^{\mathrm{t}}}\right)-\sum_{\mathrm{t}=1}^{\infty} \frac{\mathrm{Fcd}}{\left(1+\mathrm{kd}_{\mathrm{t}}\right)^{\mathrm{t}}}+ \\
& +\sum_{\mathrm{t}=1}^{\infty}\left(\mathrm{Fcd}_{\mathrm{t}} \cdot \frac{\left(\mathrm{ke}_{\theta \mathrm{t}}-\mathrm{kd}_{\mathrm{t}}\right)}{\left(1+\mathrm{kd}_{\mathrm{t}}\right)^{\mathrm{t}} \cdot\left(1+\mathrm{ke}_{\theta \mathrm{t}}\right)^{\mathrm{t}}}\right)=\mathrm{VA}_{0}-\Delta \mathrm{VA}_{\mathrm{o}}-\mathrm{D}_{\mathrm{o}}+\mathrm{GD}_{0} .
\end{aligned}
$$

Está demonstrado que a equivalência de valor do capital próprio, quando avaliado pelo fluxo de caixa livre para o acionista, somente existe, quando avaliados o ativo e a dívida em conjunto com o ganho da dívida e a variação de valor do ativo para o acionista (da mesma forma como também se pode adicionar o benefício fiscal e sua perda econômica, conforme equação 13).

Assim, a proposição deste trabalho independe da validade ou não das proposições de Modigliani e Miller, assim como o uso indevido e distorcivo do WACC é evitado. No caso de as referidas proposições não serem aplicáveis 
em uma realidade com fluxos de caixa de capitais de terceiros com risco, custos de agência, custos de transação etc., a proposição deste trabalho tornase ainda mais relevante, porque, novamente, permite a evidenciação individualizada dos efeitos do uso do capital de terceiros por entidades.

\section{Avaliação COMPLETA}

O modelo de avaliação, deduzido e completo, leva em consideração três elementos distintos dos modelos tradicionais: o ganho na dívida, a parcela de variação de valor do ativo para o acionista e a parcela de variação de valor do

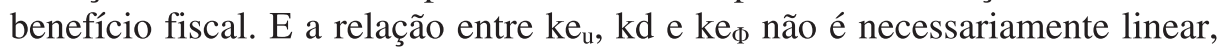
como dada pelas proposições de Modigliani e Miller, pois o custo do capital próprio desta dedução já abrange outros fatores de custo do capital próprio, tais como custos de agência, custos de monitoramento, e outros aspectos que influenciam o custo do capital próprio com dívidas não abrangidas pelas proposições. Por não se objetivar estabelecer a relação entre o custo do capital próprio com e sem dívidas, assume-se que esse custo seja dado exogenamente.

O valor justo do ativo operacional, na presença de imposto de renda, depende exclusivamente de seu fluxo de caixa e de seu risco básico, e é expresso por $\mathrm{VA}_{0}=\sum_{\mathrm{t}=1}^{\infty}\left(\frac{\mathrm{Fca}_{\mathrm{t}}-\mathrm{IRop}_{\mathrm{t}}}{\left(1+\mathrm{ke}_{\mathrm{ut}}\right)^{\mathrm{t}}}\right)$, onde $\mathrm{ke}_{\mathrm{ut}}$ é o custo do capital próprio sem dívidas no momento t. O valor de mercado da dívida é expresso por $\mathrm{D}_{0}=\sum_{\mathrm{t}=1}^{\infty} \frac{\left(\mathrm{Fcd}_{\mathrm{t}}\right)}{\left(1+\mathrm{kd}_{\mathrm{t}}\right)^{\mathrm{t}}}$, onde $\mathrm{kd}_{\mathrm{t}}$ é o custo do capital de terceiros no momento t. Note-se que o custo da dívida é o integral, sem redução do imposto de renda. O valor do benefício fiscal da dívida é expresso por $\mathrm{VBF}_{0}=\sum_{\mathrm{t}=1}^{\infty} \frac{\mathrm{Bf}_{\mathrm{t}}}{\left(1+\mathrm{ke}_{\mathrm{ut}}\right)^{\mathrm{t}}}$. O ganho da dívida é expresso por $\mathrm{GD}_{\mathrm{o}}=\sum_{\mathrm{t}=1}^{\infty} \mathrm{Fcd}_{\mathrm{t}} \frac{\left(\mathrm{ke}_{\theta t}-\mathrm{kd}_{\mathrm{t}}\right)}{\left(1+\mathrm{ke}_{\theta \mathrm{t}}\right)^{\mathrm{t}}\left(1+\mathrm{kd}_{\mathrm{t}}\right)^{\mathrm{t}}}$. A variação de valor do ativo para o acionista é $\Delta \mathrm{VA}_{0}=\sum_{\mathrm{t}=1}^{\infty}\left(\mathrm{Fca}_{\mathrm{t}}-\mathrm{IRop}_{\mathrm{t}}\right) \frac{\left(\mathrm{keu}_{\theta t}-\mathrm{ke}_{\mathrm{ut}}\right)}{\left(1+\mathrm{ke}_{\theta t}\right)^{\mathrm{t}}\left(1+\mathrm{ke}_{\mathrm{ut}}\right)^{\mathrm{t}}}$. A variação do valor do benefício fiscal é $\Delta \mathrm{VBF}_{\mathrm{o}}=\sum_{\mathrm{t}=1}^{\infty}\left(\mathrm{Bf}_{\mathrm{t}}\right) \frac{\left(\mathrm{ke}_{\mathrm{ut}}-\mathrm{ke}_{\theta t}\right)}{\left(1+\mathrm{ke}_{\mathrm{ut}}\right)^{\mathrm{t}}\left(1+\mathrm{ke}_{\theta t}\right)^{\mathrm{t}}}$. 
O modelo completo da avaliação da firma, partindo-se do modelo conceitual Valor Presente Ajustado, que considera que o valor da firma é composto pelo valor do ativo, independentemente da sua forma de financiamento, mais os 'efeitos colaterais', derivados da interação entre estrutura de capital de investimentos, possibilita que o valor da firma seja decomposto nos seus mais diversos componentes, resultando na Anatomia do Valor da Firma. É apresentado da seguinte forma:

$$
\begin{aligned}
& \mathrm{VF}_{0}=\sum_{\mathrm{t}=1}^{\infty}\left(\frac{\mathrm{Fca}_{\mathrm{t}}-\mathrm{IRop}_{\mathrm{t}}}{\left(1+\mathrm{ke}_{\mathrm{ut}}\right)^{\mathrm{t}}}\right) \sum_{\mathrm{t}=1}^{\infty} \frac{\left(\mathrm{Bf}_{\mathrm{t}}\right)}{\left(1+\mathrm{ke}_{\mathrm{ut}}\right)^{\mathrm{t}}}+\sum_{\mathrm{t}=1}^{\infty} \mathrm{Fcd}_{\mathrm{t}} \frac{\left(\mathrm{ke}_{\theta t}-\mathrm{kd}_{\mathrm{t}}\right)}{\left(1+\mathrm{ke}_{\theta t}\right)^{\mathrm{t}}\left(1+\mathrm{kd}_{\mathrm{t}}\right)^{\mathrm{t}}}+ \\
& +\sum_{\mathrm{t}=1}^{\infty}\left(\mathrm{Fca}_{\mathrm{t}}-\mathrm{IRop}_{\mathrm{t}}\right)\left[\frac{\left(\mathrm{keu}_{\theta t}-\mathrm{ke}_{\mathrm{ut}}\right)}{\left(1+\mathrm{ke}_{\theta t}\right)^{\mathrm{t}}\left(1+\mathrm{ke}_{\mathrm{ut}}\right)^{\mathrm{t}}}\right]+\sum_{\mathrm{t}=1}^{\infty}\left(\mathrm{Bf}_{\mathrm{t}}\right) \frac{\left(\mathrm{ke}_{\mathrm{ut}}-\mathrm{ke}_{\theta t}\right)}{\left(1+\mathrm{ke}_{\mathrm{ut}}\right)^{\mathrm{t}}\left(1+\mathrm{ke}_{\theta t}\right)^{\mathrm{t}}}+\mathrm{AF}_{0}
\end{aligned}
$$

Equação 16

A equação 16 pode ser reescrita em termos dos componentes que formam a anatomia do valor da firma:

$$
\mathrm{VF}_{0}=\mathrm{VA}_{0}+\mathrm{Bf}_{0} \mathrm{GD}_{0} \Delta \mathrm{VA}_{0}+\Delta \mathrm{Bf}_{0}+\mathrm{AF}_{0}
$$

Equação 17

Excluindo-se o valor de mercado da dívida da equação 17, tem-se o mesmo valor do capital próprio, quando obtido pela abordagem direta, ou seja, pelo desconto do fluxo de caixa livre para o acionista ao custo do capital próprio. O valor do capital próprio e sua composição de valor são obtidos da seguinte forma:

$$
\begin{aligned}
& \mathrm{VEa}_{0}=\sum_{\mathrm{t}=1}^{\infty}\left(\frac{\mathrm{Fca}_{\mathrm{t}}-\mathrm{IRop}_{\mathrm{t}}}{\left(1+\mathrm{ke}_{\mathrm{ut}}\right)^{\mathrm{t}}}\right) \sum_{t=1}^{\infty} \frac{\left(\mathrm{Bf}_{\mathrm{t}}\right)}{\left(1+\mathrm{ke}_{\mathrm{ut}}\right)^{\mathrm{t}}} \sum_{t=1}^{\infty} \mathrm{Fcd}_{\mathrm{t}} \frac{\left(\mathrm{ke}_{\theta t}-\mathrm{kd}_{\mathrm{t}}\right)}{\left(1+\mathrm{ke}_{\theta t}\right)^{\mathrm{t}}\left(1+\mathrm{kd}_{\mathrm{t}}\right)^{\mathrm{t}}}+ \\
& +\sum_{\mathrm{t}=1}^{\infty}\left(\mathrm{Fca}_{\mathrm{t}}-\mathrm{IRop}_{\mathrm{t}}\right)\left[\frac{\left(\mathrm{keu}_{\theta t}-\mathrm{ke}_{\mathrm{ut}}\right)}{\left(1+\mathrm{ke}_{\theta t}\right)^{\mathrm{t}}\left(1+\mathrm{ke}_{\mathrm{ut}}\right)^{\mathrm{t}}}\right]+\sum_{\mathrm{t}=1}^{\infty}\left(\mathrm{Bf}_{\mathrm{t}}\right) \frac{\left(\mathrm{ke}_{\mathrm{ut}}-\mathrm{ke}_{\theta t}\right)}{\left(1+\mathrm{ke}_{\mathrm{ut}}\right)^{\mathrm{t}}\left(1+\mathrm{ke}_{\theta t}\right)^{\mathrm{t}}}- \\
& -\mathrm{D}_{0}+\mathrm{AF}_{0} \quad \text { Equação 18 }
\end{aligned}
$$

A equação 18 pode ser reescrita em termos de seus componentes que formam a anatomia do valor do capital próprio:

$$
\mathrm{VEa}_{0}=\mathrm{VA}_{0_{+}} \mathrm{Bf}_{0_{+}} \mathrm{GD}_{0_{+}} \Delta \mathrm{VA}_{0}+\Delta \mathrm{Bf}_{0}-\mathrm{D}_{0}+A F_{0}
$$

Equação 19

A relação que existe entre a equação 19 e as proposições de $\mathrm{MM}$ é que o capital próprio resultante das aplicações de $\mathrm{MM}$, por ocasião da não observância de suas premissas básicas, fica enviesado. A diferença entre o 
valor obtido pela simples aplicação das proposições de Modigliani e Miller (e não observadas suas premissas) e pela metodologia proposta, é a soma dos três elementos propostos: o ganho na dívida, a variação do valor dos ativos e do benefício fiscal.

Portanto, a equação 19 é equivalente a:

$$
\mathrm{VEa}_{0}=\mathrm{E}_{\mathrm{MM}_{0}}+\mathrm{GD}_{0}+\Delta \mathrm{VA}_{0}+\Delta \mathrm{BF}_{0}
$$

Equação 20,

onde:

- $\mathrm{E}_{\mathrm{MM} 0}$ é o valor do capital próprio pedido pelo fluxo de caixa livre descontado pelo custo do capital próprio, dado pela segunda proposição de Modigliani e Miller.

\section{Considerações Finais}

No presente trabalho foi visto que o uso do WACC na avaliação de empresas resulta em valores da firma e do capital próprio fechados, herméticos e não analíticos. Para que se conheça a composição analítica desses valores, é deduzida a metodologia alternativa de avaliação de empresas (anatomia do valor da empresa), partindo-se do relaxamento das premissas das proposições de Modigliani e Miller.

A metodologia de avaliação discutida possibilita a identificação isolada dos valores que compõem a firma e o capital próprio, e o estudo de seus componentes. Nos termos utilizados neste trabalho, é verificada a possibilidade de se estudar a composição analítica do valor da firma e do capital próprio.

Com relação a esses valores, a proposta de avaliação de empresas deste trabalho é consistente com a moderna teoria de finanças, que versa que o valor do ativo independe da sua forma de financiamento. Os valores decorrentes da interação da estrutura de capital com os investimentos não fazem parte do valor dos ativos, mas, sim, da firma, e podem ser identificados isoladamente.

Conforme os argumentos desenvolvidos, a presença de capital de terceiros impede que os benefícios totais proporcionados pelos ativos sejam aproveitados integralmente pelos donos do capital próprio. E essa parcela de "não aproveitamento' de valor é identificada e segregada da parte do valor dos ativos operacionais. Merece destaque que a proposta de avaliação de empresas deste 
trabalho não depende do uso do WACC, sendo que os custos relevantes são o custo do capital próprio sem dívidas (custo do capital próprio desalavancado, ou com o risco básico dos ativos), o custo do capital próprio na presença de dívidas (custo do capital próprio alavancado) e o custo do capital de terceiros.

A anatomia de valor também considera os impostos corporativos, mais especificamente, o benefício fiscal proporcionado pela dívida.

A metodologia deduzida, portanto, pode ser utilizada genericamente para a análise da composição do valor da firma e do capital próprio, pois proporciona que esses sejam desmembrados em:

- valor dos ativos operacionais (investimentos operacionais), independentemente de como são financiados;

- efeito do valor da dívida para a firma e para o capital próprio (ganho da dívida);

- efeito da alavancagem sobre os valores dos ativos operacionais (investimentos operacionais), isoladamente;

- efeito conjunto dos valores dos ativos operacionais e estrutura de capital.

Com relação aos desdobramentos futuros, a anatomia de valor da firma e do capital próprio proporciona uma capacidade analítica de entendimento do comportamento passado dos valores justos dos ativos e do capital próprio, assim como permite uma análise de desempenho dos ativos, do financiamento e da interação dessas duas atividades.

Um assunto passado à margem neste trabalho, que sugere pesquisas futuras, é a utilização do Ganho da Dívida [GD] para a avaliação de reestruturação de dívidas. Tal aspecto é relevante, pois a utilização do GD implica identificação dos valores que serão adicionados (ou destruídos) em função de troca de dívidas.

Certamente, a aplicação empírica da anatomia de valor deve ser desenvolvida em trabalhos futuros, para corroborar, ou não, a aplicabilidade, principalmente no Brasil, da metodologia desenvolvida e dos conceitos que a fundamentaram, e também para corroborar a conclusão de que o uso do WACC não é essencial na avaliação de empresas.

Um último comentário refere-se à utilização do modelo proposto, assumindo comportamento estocástico dos componentes, para estudo de estrutura ótima de capital, por meio de otimização dos componentes de valor da firma.

Artigo recebido em 16.10.2006. Aprovado em 28.08.2007. 


\section{NOTAS}

${ }^{1}$ Capital de terceiros no contexto desse artigo implica somente os passivos onerosos. Os passivos de financiamentos são considerados no capital de giro líquido.

${ }^{2} \mathrm{O}$ uso do WACC, com respeito a todas as suas premissas, retorna um valor agregado da empresa, e indiretamente do capital próprio. A presente proposta é justamente decompor esse valor nas suas composições operacionais, de estrutura de capital e da interação entre essas partes.

${ }^{3}$ Risco básico refere-se ao custo do capital próprio na ausência de dívidas, que, por sua vez, representa o custo de oportunidade exclusivamente dos investimentos.

${ }^{4}$ O Ganho da Dívida [GD], em situações em que o custo do capital de terceiros seja superior ao custo do capital próprio, na realidade é uma perda de valor, e se apresentará como um ganho 'negativo'. Isso ocorre pelo fato de, pelo menos teoricamente, ser o custo do capital de terceiros inferior ao do capital próprio. Assim espera-se que, teoricamente, o Ganho da Dívida seja efetivamente um ganho.

${ }^{5}$ Trabalhos empíricos posteriores podem ou não refutar tal assertiva teórica.

${ }^{6}$ Em uma situação em que a capacidade da gerência de renegociar dívidas na insuficiência de caixa livre da empresa é nula (por premissa), as dívidas atuais somente poderão ser pagas na existência de fluxo livre para empresa. Também entendemos que isso não seja garantia para pagamento de dívida. Pode-se argumentar que se houver fluxo livre da empresa, e demanda contratual para pagamento de dívida, esse será utilizado até a extensão contratual, se isso for possível (caixa livre superior aos pagamentos de dívida). Ao se considerar a capacidade não nula de renegociação da dívida, esta deverá levar em conta as novas taxas de juros; logo avaliar os novos e possíveis ganhos da dívida. E isso é aspecto relevante nessa decisão que não será abordado neste artigo.

${ }^{7}$ A utilização de capital de terceiros ao invés de capital próprio somente tem sentido, quando o custo do capital de terceiros é inferior ao custo do capital próprio, ou quando existem restrições em se obter capital de terceiros. No primeiro contexto podem ser as várias explicações possíveis encontradas na literatura para uso do capital de terceiros, tais como fator mitigante de custos de agência, sinalização para o mercado etc. Todas elas têm um único objetivo comum: maximizar a rentabilidade do capital próprio, de uma forma direta (como financiamentos diretos a projetos de investimento) ou indireta (como forçar os administradores de empresas a não esbanjarem fluxo de caixa livre da firma por meio de comprometimento deste com pagamento de dívidas). Quando existem restrições de crédito, entende-se que também somente faz sentido o uso de capital de terceiros quando existem efetivas possibilidades de investimentos com resultados positivos, mesmo que apresentem riscos maiores. Enfim, o capital de terceiros é encarado tido como fator de alavancagem de resultados para o capital próprio, portanto, a princípio, um fator positivo para a vida empresarial.

${ }^{8}$ Cabe ressaltar que capitais de terceiros são importantes para que as oportunidades de investimentos que agreguem valor aos acionistas possam ser implementadas sem o comprometimento do capital próprio. O que este artigo trata é justamente do efeito em termos de valor para o acionista que esse capital de terceiros gera.

${ }^{9}$ Nesse ponto ainda introdutório do trabalho, assume-se que o fluxo de caixa da dívida refere-se somente aos juros, e que o principal será pago no infinito. No momento atual podemos verificar empiricamente que essa premissa não é absurda, visto que nos últimos anos muitas empresas alavancaram suas estruturas de capital com títulos perpétuos de dívida.

${ }^{10}$ Os efeitos colaterais são valores presentes líquidos positivos ou negativos. 
${ }^{11}$ Conforme Myers (1974), é quanto a capacidade de dívida da empresa $\left(\mathrm{Z}_{\mathrm{t}}\right)$ é alterada por causa do projeto j. Nesses termos, são incluídos os efeitos de valor decorrentes da interação do investimento com a estrutura de capital da empresa.

${ }^{12}$ Os modelos tradicionais podem ser encontrados em vasta literatura, tais como em Siegel, 1985; Vélez-Pareja e Tham, 2005; Van Horne, J. C. (1977). Financial management and policy (11th ed.). EUA: Prentice Hall, Ruback, 2002, entre diversas outras fontes de periódicos e manuais de finanças.

${ }^{13}$ Com relação ao benefício fiscal, podem ser também incluídos outros itens, tais com despesa de depreciação, juros sobre capital próprio, entre outros. Mas isso não será explicitamente tratado nesse trabalho.

${ }^{14}$ Foram consideradas alíquotas distintas de imposto operacional e do benefício fiscal nos anos de projeções explícitas para permitir alíquotas efetivas operacionais diferente das nominais, e também para deixar claro que alíquotas diferentes, quando tratadas adequadamente, não viesam os cálculos.

\section{RefERÊNCIAS BibliográficAs}

Arditti, F. D. (1973).

The Weighed average cost of capital: some questions on its definition, interpretation, and use. Journal of Finance, 28(4), 1001-1007.

Beranek, W. (1978).

Some new capital budgeting theorems. Journal of Financial and Quantitative Analysis, 13(5), 809-823.

Boness, A. J. (1964).

A pedagogic note on the cost of capital. Journal of Finance, 19(1), 99-106.

Bradley, M.,

Gregg, A., \&

Kim, E.H. (1984).

On the existence of and optimal capital structure: theory and evidence. Journal of Finance, 39(3), 857-878.

Brennan, M. J. (1973).

A new look at the weighed average cost of capital. Journal of Business Finance, 5(1), 24-30.
Brigham, E. F.,

Shome, D. K., \&

Vinson, S. R. (1985).

Cost of capital estimation: the risk premium approach to measuring a utility's cost of equity. Financial Management, 14(1), 33-45.

Choi, J. J. (1988).

Debt financing and the cost of capital in the neoclassical investment model. American Economist, 32(1), 19-23.

Durand, D. (1989).

Reflections on the MM propositions: thirty years latter. Afterthoughts on a controversy with MM, plus new thoughts on growth and the cost of capital. Financial Management, 18(2), $12-18$.

Fama, E. F., \&

Jensen, M. C. (1983).

Agency problems and residual claims. Journal of Law \& Economics, 26(2), 327-350. 
Fernández, P. (2004).

The value of tax shields is NOT equal to the present value of tax shields. Journal of Financial Economics, 73(1), 145-165.

Fernández, P. (2006, December 27).

Valuing companies by cash flow discounting: ten methods and nine theories. EFMA 2002 London Meetings.

Social Science Research Network. Recuperado em 23 março, 2007, de http:/ /ssrn.com/abstract=256987

Ferson, W. E., \&

Locke, D. H. (1998).

Estimating the cost of capital through time: an analysis of the sources of error. Management Science, 44(4), 485-500.

Freeman, M., \&

Hobbes, G. (1991).

Capital Budgeting: theory versus practice. Australian Accountant, 61(8), 36-41.

Gordon, M. J. (1989).

Corporate finance under the MM theorems. Financial Management, 18(2), 19-28.

Haley, C. W., \&

Schall,L.D.(1978).

Problems with the concept of the cost of capital. Journal of Financial and Quantitative Analysis, 13(5), 847-870.

Harris, M., \&

Raviv,A. (1991).

The theory of capital structure. Journal of Finance, 46(1), 297-355.

Henderson, G. V., Jr. (1979).

In defense of the weighted average cost of capital. Financial Management, 8(3), 57-61.
Jensen, M. C. (1986).

Agency costs of free cash flow, corporate finance, and takeovers. American Economic Review, 76(2), 323329.

Jensen, M. C., \&

Meckling, W. H. (1976).

Theory of the firm: managerial behavior, agency costs and ownership structure. Journal of Financial Economics, 3(4), 305-360.

Kaplan, S. N., \&

Ruback, R. S. (1995).

The valuation of cash flow forecast: an empirical analysis. Journal of Finance, 50(4), 1059-1093.

Kincheloe, S. C. (1990).

The weighted average cost of capital: the correct discount rate. Appraisal Journal, 58(1), 88-95.

Linke, C. M., \&

Kim, M. K. (1974).

More on the weighed average cost of capital: a comment and analysis. Journal of Financial and Quantitative Analysis, 9(6), 1069-1080.

Löffler, A. (1998, February).

WACC approach and nonconstant leverage ratio. Recuperado em 23 dezembro, 2004, de http://ssrn.com/ abstract $=60937$

Masulis, R. W. (1983).

The impact of capital structure change on firm value: some estimates. Journal of Finance, 38(1), 107-126. 
Mcconnell, J. J., \&

Sandberg, C. M. (1975).

The weighted average cost of capital: some questions on its definition, interpretation, and use: comment. Journal of Finance, 30(3), 883-886.

Miles, J. A., \&

Ezzell, J.R.(1980).

The weighed average cost of capital, perfect capital markets, and project life: a clarification. Journal of Financial and Quantitative Analysis, 15(3), 719730.

Miles, J.A., \&

Ezzell, J.R.(1985).

Reformulating tax shield valuation: a note. Journal of Finance, 40(5), 14851492.

Miller, M.H. (1977).

Debt and taxes. Journal of Finance, 32(2), 261-275.

Miller, M.H. (1986).

Financial innovation: the last twenty years and the next. Journal of Financial and Quantitative Analysis, 21(4), 459-471.

Miller, M.H. (1988).

The modigliani-miller propositions after thirty years. Journal of Economic Perspective, 2(4), 99-120.

Miller, M.H. (1991).

Leverage. Journal of Finance, 46(2), 479-488.

Miller, M.H., \&

Modigliani, F. (1961).

Dividend policy, growth, and the valuation of shares. Journal of Business, 34(4), 411-433.
Miller, M. H., \&

Modigliani, F. (1963).

Dividend policy and market valuation: a reply. Journal of Business, 34(1), 116119.

Miller, M.H., \&

Sholes, M. S. (1982).

Dividends and taxes: some empirical evidence. Journal of Political Economy, 90(6), 1118-1141.

Modigliani, F. (1982).

Debt, dividend policy, taxes, inflation and market valuation. Journal of Finance, 37(2), 255-273.

Modigliani, F. (1983).

Debt, dividend policy, taxes, inflation and market valuation: erratum. The Journal of Finance, 38(3), 1041-1042.

Modigliani, F. (1988).

MM - Past, present, future. Journal of Economic Perspective, 2(4), 149-158.

Modigliani, F., \&

Miller, M.H. (1958).

The cost of capital, corporation finance and theory of investment. American Economic Review, 48(3), 261-297.

Modigliani, F., \&

Miller, M.H. (1959).

The cost of capital, corporation finance and theory of investment: reply. American Economic Review, 49(4), 655669.

Modigliani, F., \&

Miller, M.H.(1963).

Corporate income, taxes and the cost of capital: a correction. American Economic Review, 53(3), 433-443. 
Modigliani, F., \&

Miller, M.H. (1969).

Reply to heins and sprenkel. American Economic Review, 59(4), 592-595.

Myers, S. C. (1974).

Interactions of corporate financing and investment decisions - Implications for capital budgeting. Journal of Finance, 29(1), 1-25.

Myers, S. C. (1977).

Interactions of corporate financing and investment decisions - Implications for capital budgeting: reply. Journal of Finance, 32(1), 218-220.

Myers, S. C. (1984).

The capital structure puzzle. Journal of Finance, 39(3), 575-592.

Myers, S. C. (2000).

Outside equity. Journal of Finance, 55(3), 1005-1037.

Myers, S. C. (2001).

Capital structure. Journal of Economic Perspectives, 15(2), 81-102.

Nantell, T. J., \&

Carlson, C. R. (1975).

The cost of capital as a weighed average. Journal of Finance, 30(5), 1343-1355.

Paulo, S. B. S. (1992).

The weighted average cost of capital: a caveat. Engineering Economist, 37(2), 178-183.

Reilly, R. R., \&

Wecker, W. E. (1973).

On the weighed average cost of capital. Journal of Financial and Quantitative Analysis, 8(1), 123-126.
Robicheck, A. A., \&

Myers, S. C. (1966a).

Valuation of the firm: effects of uncertainty in a market context. Journal of Finance, 21(2), 215-227.

Robicheck, A. A., \&

Myers, S. C. (1966b).

Problems in the theory of optimal capital structure. Journal of Financial and Quantitative Analysis, 1(2), 1-35.

Robicheck, A. A., \&

Myers, S. C. (1968).

Valuation under uncertainty: comment. Journal of Financial and Quantitative Analysis, 3(4), 479-483.

Roncaglio, F., \&

Zanetti, L. (2004).

On the equivalence between the APV and the WACC approach in a growing levered firm [Basel Meetings Paper]. University of Bocconi. Social Science Research Network. Recuperado em 23 dezembro, 2004, de http://ssrn.com/ abstract $=493363$

Ruback, R. S. (2002).

Capital cash flows: a simple approach to valuing risky cash flows. Financial Management, 31(2), 85-103.

Siegel, J. J. (1985).

The application of the DCF methodology for determining the cost of equity capital. Financial Management, 14(1), 46-53.

Vélez-Pareja, I., \&

Tham, J. (2005, August 7).

A note on the weighted average cost of capital WACC. Recuperado em 27 agosto, 2005, de http://ssrn.com/ abstract $=254587$ 
Wang, L. K. (1994).

The weighted average cost of capital and marginal costing: a clarification. Engineering Economist, 37(2), 187-191.

Weston, F. J. (1989).

What MM have wrought. Financial Management, 18(2), 29-36.

Wood, J. S., \&

Leitch, G. (2004).

Interactions of corporate financing and investment decisions: the financing present value [FPV] approach to evaluating investment projects that change capital structure. Managerial Finance, 30(2), 16-37.

Woods, J. C., \&

Randall, M. R. (1989).

The net present value of future investment opportunities: its impact on shareholder wealth and implications for capital budgeting theory. Financial Management, 18(2), 85-92. 


\section{APÊNDICE}

\section{Exemplo do Modelo Completo}

Este exemplo tem o objetivo de demonstrar numericamente as equivalências demonstradas no item 4 . O exemplo desenvolvido mostra que o valor do capital próprio obtido pela anatomia do valor é igual ao valor do capital próprio calculado conforme as proposições de Modigliani e Miller (pelo custo do capital próprio com dívidas e pelo wacc) mais os ajustes do ganho da dívida e das variações de valor do ativo e do benefício fiscal para o acionista. Sejam as projeções contábeis do período explícito dadas a seguir:

\begin{tabular}{|l|c|c|c|c|c|c|c|}
\hline BP (contábil) & $\mathbf{0}$ & $\mathbf{1}$ & $\mathbf{2}$ & $\mathbf{3}$ & $\mathbf{4}$ & $\mathbf{5}$ & $\mathbf{6}$ \\
\hline Ativo & 100,00 & 110,00 & 114,00 & 116,00 & 118,00 & 120,00 & 120,00 \\
\hline Dívida & 60,00 & 60,00 & 60,00 & 60,00 & 60,00 & 60,00 & 60,00 \\
\hline Patrimônio Líquido & 40,00 & 40,00 & 44,00 & 46,00 & 48,00 & 50,00 & 50,00 \\
\hline DRE (contábil) & $\mathbf{0}$ & $\mathbf{1}$ & $\mathbf{2}$ & $\mathbf{3}$ & $\mathbf{4}$ & $\mathbf{5}$ & $\mathbf{6}$ \\
\hline Lucro operacional & & 20,00 & 24,20 & 27,36 & 30,16 & 33,04 & 36,00 \\
\hline IR op & & $(8,00)$ & $(7,26)$ & $(9,58)$ & $(11,46)$ & $(11,56)$ & $(12,60)$ \\
\hline Despesas financeiras & $(5,40)$ & $(6,00)$ & $(6,90)$ & $(7,80)$ & $(8,40)$ & $(9,00)$ \\
\hline BF & & 1,89 & 2,10 & 2,42 & 2,73 & 2,94 & 3,15 \\
\hline Lucro líquido & & 8,49 & 13,04 & 13,30 & 13,63 & 16,02 & 17,55 \\
\hline Fl CX (realizado) & $\mathbf{0}$ & $\mathbf{1}$ & $\mathbf{2}$ & $\mathbf{3}$ & $\mathbf{4}$ & $\mathbf{5}$ & $\mathbf{6}$ \\
\hline do Ativo & $(100,00)$ & 2,00 & 12,94 & 15,78 & 16,70 & 19,48 & 23,40 \\
\hline da Dívida & $(60,00)$ & 5,40 & 6,00 & 6,90 & 7,80 & 8,40 & 9,00 \\
\hline $\begin{array}{l}\text { Benefício fiscal } \\
\text { dos Sócios }\end{array}$ & $(40,00)$ & $(1,89$ & 2,10 & 2,42 & 2,73 & 2,94 & 3,15 \\
\hline
\end{tabular}

As premissas utilizadas foram:

. Fluxos de caixa explícitos nos cinco primeiros anos e perpetuidade, a partir do sexto ano;

. Todos os dados do sexto período se repetem até a perpetuidade;

. Não há necessidade de reinvestimento operacional a partir do sexto ano;

. Todo o fluxo de caixa livre dos sócios é retirado sob a forma de dividendos;

. Todos os juros são pagos no final de cada período;

. O principal da dívida será pago em $+\infty$; 
. Em $+\infty$ a empresa será liquidada pelos valores contábeis nessa data; portanto, o valor presente dessa liquidação é desprezível;

- As alíquotas de imposto de renda operacional ${ }^{(14)}$ e nominal (para cálculo do benefício fiscal foram):

\begin{tabular}{|l|l|l|l|l|l|l|}
\hline DADOS & $\mathbf{1}$ & $\mathbf{2}$ & $\mathbf{3}$ & $\mathbf{4}$ & $\mathbf{5}$ & $\mathbf{6}$ \\
\hline IR op & $40,00 \%$ & $30,00 \%$ & $35,00 \%$ & $38,00 \%$ & $35,00 \%$ & $35,00 \%$ \\
\hline IR non & $35,00 \%$ & $35,00 \%$ & $35,00 \%$ & $35,00 \%$ & $35,00 \%$ & $35,00 \%$ \\
\hline
\end{tabular}

Os dados para cálculos dos parâmetros de mercado são dados a seguir. As premissas adicionais são:

- Assume-se que os custos do capital próprio desalavancado para cada período podem ser estimados em função unicamente do risco dos ativos;

- Assume-se que os custos da dívida não sejam constantes nem livres de risco nos períodos explícitos, e que têm alguma relação com o nível de endividamento da empresa, com o risco dos ativos e com outros parâmetros não dados explicitamente;

- Assume-se que o custo do capital próprio com dívidas não segue as proposições de MM, por dois fatos principais: a dívida não é livre de risco e outros fatores (não explicitados) externos afetam o custo do capital próprio com dívidas (custos de agência, custos de falência etc.). Por esses motivos são assumidos como dado de outras fontes que não as proposições de MM.

. Os dados são:

\begin{tabular}{|l|l|l|l|l|l|l|}
\hline DADOS & $\mathbf{1}$ & $\mathbf{2}$ & $\mathbf{3}$ & $\mathbf{4}$ & $\mathbf{5}$ & $\mathbf{6}$ \\
\hline ke $_{\mathbf{u}}$ (capital próprio desalavancado) & $15,00 \%$ & $15,50 \%$ & $16,00 \%$ & $16,50 \%$ & $17,00 \%$ & $18,00 \%$ \\
\hline Kd (custo da dívida) $^{\text {ke }_{\mathbf{L}} \text { (exógeno) }}$ & $9,00 \%$ & $10,00 \%$ & $11,50 \%$ & $13,00 \%$ & $14,00 \%$ & $15,00 \%$ \\
\hline
\end{tabular}

Na data-base da avaliação, $\mathrm{t}=0$, são feitas duas avaliações da empresa e do capital próprio. A primeira é a tradicional, usando-se as proposições de Modigliani e Miller e o wacc. A segunda avaliação é feita utilizando-se o modelo proposto neste trabalho.

\section{Primeira Avaliação: Aplicação das Proposições de MM}

A "regra" mais simples e corriqueira para se determinar o valor de mercado do capital próprio na data 0 consiste em utilizar a abordagem indireta, pela qual o valor do capital próprio é obtido por diferença entre o valor do ativo e o valor da dívida. Os custos do capital próprio desalavancado são utilizados para se calcular 
o valor presente no momento $\mathrm{t}=0$ do ativo e do benefício fiscal. Os fluxos de caixa de cada um dessas figuras e seus custos anuais e acumulados são:

\begin{tabular}{|l|c|c|c|c|c|c|}
\hline DADOS & $\mathbf{1}$ & $\mathbf{2}$ & $\mathbf{3}$ & $\mathbf{4}$ & $\mathbf{5}$ & $\mathbf{6}$ \\
\hline $\mathbf{k e}_{\mathrm{u}}$ & $15,00 \%$ & $15,50 \%$ & $16,00 \%$ & $16,50 \%$ & $17,00 \%$ & $18,00 \%$ \\
\hline $\mathbf{k e}_{\mathrm{u}}$ (acumulado) & $15,00 \%$ & $32,83 \%$ & $54,08 \%$ & $79,50 \%$ & $110,01 \%$ & $147,82 \%$ \\
\hline Fl CX (realizado) & $\mathbf{1}$ & $\mathbf{2}$ & $\mathbf{3}$ & $\mathbf{4}$ & $\mathbf{5}$ & $\mathbf{6}$ \\
\hline do Ativo & 2,00 & 12,94 & 15,78 & 16,70 & 19,48 & 23,40 \\
\hline do Benefício Fiscal & 1,89 & 2,10 & 2,42 & 2,73 & 2,94 & 3,15 \\
\hline
\end{tabular}

Considerando que os dados do período 6 se perpetuam, tem-se que em $\mathrm{t}=0 \mathrm{o}$ valor presente do fluxo de caixa livre dos ativos é igual a \$102,20, e o valor do benefício fiscal nessa mesma data é igual a $\$ 16,05$, resultando no valor total de mercado da firma de $\$ 118,50$. Os custos do capital de terceiros e os fluxos de caixa líquidos da dívida, parâmetros para o cálculo do valor de mercado da dívida em t=0, são:

\begin{tabular}{|l|c|c|c|c|c|c|}
\hline DADOS & $\mathbf{1}$ & $\mathbf{2}$ & $\mathbf{3}$ & $\mathbf{4}$ & $\mathbf{5}$ & $\mathbf{6}$ \\
\hline Kd & $9,00 \%$ & $10,00 \%$ & $11,50 \%$ & $13,00 \%$ & $14,00 \%$ & $15,00 \%$ \\
\hline Kd (acumulado) & $9,00 \%$ & $19,90 \%$ & $33,69 \%$ & $51,07 \%$ & $72,22 \%$ & $98,05 \%$ \\
\hline Fl CX (realizado) & $\mathbf{1}$ & $\mathbf{2}$ & $\mathbf{3}$ & $\mathbf{4}$ & $\mathbf{5}$ & $\mathbf{6}$ \\
\hline da Dívida & 5,40 & 6,00 & 6,90 & 7,80 & 8,40 & 9,00 \\
\hline
\end{tabular}

Fazendo os cálculos tem-se que o valor de mercado da dívida no momento $t=0$ é de $\$ 60,00$. O Capital próprio, no momento $t=0$, obtido por diferença entre firma e dívida,é igual a $\$ 58,25$. Pode-se chegar a esse mesmo valor por outros dois caminhos. $\mathrm{O}$ caminho direto é calculando-se o valor presente do fluxo de caixa livre para o acionista, usando o custo do capital próprio com dívidas da segunda proposição de Modigliani e Miller. Entretanto, para que tal custo seja calculado, deve-se calcular a proporção entre dívidas/capital próprio, a valores de mercado, para cada um dos anos da projeção. Como a perpetuidade se inicia no sexto período, o valor do ativo e da dívida de cada um dos anos explícitos devem ser calculados antes de se determinar o custo do capital próprio com dívidas dado por Modigliani e Miller. Usando os mesmos fluxos de caixa livres do ativo, do benefício fiscal e da dívida, dados anteriormente, tem-se o quadro a seguir, onde o valor do capital próprio é obtido por diferença entre ativo mais benefício fiscal menos a dívida.

\begin{tabular}{|l|c|c|c|c|c|c|c|}
\hline BP (mercado) & $\mathbf{0}$ & $\mathbf{1}$ & $\mathbf{2}$ & $\mathbf{3}$ & $\mathbf{4}$ & $\mathbf{5}$ & $\mathbf{6}$ \\
\hline Ativo & 102,20 & 115,53 & 120,50 & 124,00 & 127,76 & 130,00 & 130,00 \\
Benefício fiscal & 16,05 & 16,56 & 17,03 & 17,34 & 17,47 & 17,50 & 17,50 \\
\hline FIRMA & $\mathbf{1 1 8 , 2 5}$ & $\mathbf{1 3 2 , 1 0}$ & $\mathbf{1 3 7 , 5 3}$ & $\mathbf{1 4 1 , 3 4}$ & $\mathbf{1 4 5 , 2 3}$ & $\mathbf{1 4 7 , 5 0}$ & $\mathbf{1 4 7 , 5 0}$ \\
\hline Dívida & 60,00 & 60,00 & 60,00 & 60,00 & 60,00 & 60,00 & 60,00 \\
\hline PL (por diferença) & 58,25 & 72,10 & 77,53 & 81,34 & 85,23 & 87,50 & 87,50 \\
\hline PASSIVO & $\mathbf{1 1 8 , 2 5}$ & $\mathbf{1 3 2 , 1 0}$ & $\mathbf{1 3 7 , 5 3}$ & $\mathbf{1 4 1 , 3 4}$ & $\mathbf{1 4 5 , 2 3}$ & $\mathbf{1 4 7 , 5 0}$ & $\mathbf{1 4 7 , 5 0}$ \\
\hline dívida/pl & 1,03 & 0,83 & 0,77 & 0,74 & 0,70 & 0,69 & 0,69 \\
\hline
\end{tabular}


Com esses dados, tem-se a proporção dívida/capital próprio em termos de valor de mercado. Usando essas proporções para os anos explícitos e para a perpetuidade, mais os custos do capital próprio sem dívidas e os custos da dívida, têm-se os seguintes custos do capital próprio com dívidas, conforme proposições de MM, para os anos explícitos e para a perpetuidade. A tabela a seguir contempla esses dados por período e acumulados a partir do momento $t=1$.

\begin{tabular}{|l|c|c|c|c|c|c|}
\hline DADOS & $\mathbf{1}$ & $\mathbf{2}$ & $\mathbf{3}$ & $\mathbf{4}$ & $\mathbf{5}$ & $\mathbf{6}$ \\
\hline $\mathbf{k e}_{\mathbf{u}}$ & $15,00 \%$ & $15,50 \%$ & $16,00 \%$ & $16,50 \%$ & $17,00 \%$ & $18,00 \%$ \\
\hline $\mathbf{k e}_{\mathbf{u}}$ acumulado & $15,00 \%$ & $32,83 \%$ & $54,08 \%$ & $79,50 \%$ & $110,01 \%$ & $147,82 \%$ \\
\hline $\mathbf{k e}_{\mathbf{L}}$ mercado por MM & $21,18 \%$ & $20,08 \%$ & $19,48 \%$ & $19,08 \%$ & $19,11 \%$ & $20,06 \%$ \\
\hline $\mathbf{k e}_{\mathbf{L}}$ mercado por MM acumulado & $21,18 \%$ & $45,51 \%$ & $73,86 \%$ & $107,03 \%$ & $146,60 \%$ & $196,06 \%$ \\
\hline dívida/pl & 1,03 & 0,83 & 0,77 & 0,74 & 0,70 & 0,69 \\
\hline Fluxo de Caixa Livre para o Acionista & $(1,51)$ & 9,04 & 11,30 & 11,63 & 14,02 & 17,55 \\
\hline
\end{tabular}

Usando os dados da tabela acima para se calcular em $\mathrm{t}=0$ o valor presente do fluxo de caixa livre para o acionista, tem-se que esse valor é igual a $\$ 58,25$, idêntico ao obtido anteriormente por diferença entre firma e dívida. Com os dados de valor de mercado do capital próprio e do capital de terceiros, com os dados do custo do capital próprio com dívidas dado por MM e do custo da dívida, pode-se calcular o WACC para cada período e acumulado desde o momento $\mathrm{t}=1$ :

\begin{tabular}{|l|c|c|c|c|c|c|}
\hline DADOS & $\mathbf{1}$ & $\mathbf{2}$ & $\mathbf{3}$ & $\mathbf{4}$ & $\mathbf{5}$ & $\mathbf{6}$ \\
\hline WACC mercado por MM & $\mathbf{1 5 , 0 0 \%}$ & $\mathbf{1 5 , 5 0 \%}$ & $\mathbf{1 6 , 0 0 \%}$ & $\mathbf{1 6 , 5 0 \%}$ & $\mathbf{1 7 , 0 0 \%}$ & $\mathbf{1 8 , 0 0 \%}$ \\
\hline WACC mercado por MM acumulado & $15,00 \%$ & $32,83 \%$ & $54,08 \%$ & $79,50 \%$ & $110,01 \%$ & $147,82 \%$ \\
\hline
\end{tabular}

Com o WACC calculado utilizando-se os parâmetros de mercado, pode-se calcular o valor total da firma a partir do fluxo de caixa livre da firma, que inclui o fluxo de caixa livre do ativo mais o benefício fiscal:

\begin{tabular}{|l|c|c|c|c|c|c|}
\hline Fl CX (realizado) & $\mathbf{1}$ & $\mathbf{2}$ & $\mathbf{3}$ & $\mathbf{4}$ & $\mathbf{5}$ & $\mathbf{6}$ \\
\hline do Ativo & 2,00 & 12,94 & 15,78 & 16,70 & 19,48 & 23,40 \\
\hline do Benefício Fiscal & 1,89 & 2,10 & 2,42 & 2,73 & 2,94 & 3,15 \\
\hline Fluxo de Caixa da Firma & 3,89 & 15,04 & 18,20 & 19,43 & 22,42 & 26,55 \\
\hline
\end{tabular}

Utilizando-se esses fluxos de caixa livres e os dados do WACC, tem-se que o valor da firma no momento $t=0$ é igual a $\$ 118,25$, idêntico ao valor do ativo mais o valor do benefício fiscal. Subtraindo-se o valor de mercado do capital de terceiros no momento $t=0$ de $\$ 60,00$ do valor da firma, tem-se que o valor do capital próprio é de $\$ 58,25$, como previamente calculado. Ressalta-se que o valor do capital próprio está conceitualmente errado, pelo principal fato da utilização indevida das proposições de MM, já que suas premissas não são observadas. Portanto os custos do capital próprio calculados por MM são diferentes dos observáveis (exógenos). 
Em suma, por essa 'metodologia' tradicional de cálculo do valor da firma e do capital próprio aplicando-se as proposições de MM como 'regra prática', os valores calculados são evidenciados a seguir:

\begin{tabular}{|l|c|}
\hline Balanço Patrimonial obtido por MM & $\mathbf{t}=\mathbf{0}$ \\
\hline Ativo & 102,20 \\
\hline Benefício fiscal & 16,05 \\
\hline ATIVO TOTAL & $\mathbf{1 1 8 , 2 5}$ \\
\hline Dívida & 60,00 \\
\hline PL & 58,2 \\
\hline PL total & 58,25 \\
\hline PASSIVO TOTAL & $\mathbf{1 1 8 , 2 5}$ \\
\hline
\end{tabular}

Percebe-se a identificação de no máximo dois componentes do valor da firma: o ativo operacional e o benefício fiscal. Caso a firma seja avaliada pelo WACC, nem essa individualização é possível de ser observada.

\section{Segunda Avaliação: Aplicação da Proposta da Anatomia do Valor}

A segunda avaliação segue a proposta deste trabalho. Os dados relevantes para os cálculos são os mesmos fluxos de caixa já mencionados. Mas, por causa da quebra das premissas que apóiam as proposições de MM, os custos do capital próprio com dívidas são dados exogenamente, ou seja, são obtidos de outras fontes que consideram outras imperfeições de mercado, tais como custos de agência, custos de falência, custos de contratos etc. Assume-se que esses fatores são capturados no custo do capital próprio com dívidas ao invés de serem redutores dos fluxos de caixa do ativo.

Os custos do capital próprio com dívida assumidos e o fluxo de caixa livre para o acionista são dados a seguir:

\begin{tabular}{|l|c|c|c|c|c|c|}
\hline \multicolumn{1}{|c|}{ DADOS } & 1 & 2 & 3 & 4 & 5 & 6 \\
\hline kel merc (exog) & $22,00 \%$ & $22,50 \%$ & $23,00 \%$ & $23,00 \%$ & $24,00 \%$ & $\mathbf{2 2 , 0 0 \%}$ \\
\hline Fluxo de Caixa Livre para o Acionista & $(1,51)$ & $\mathbf{9 , 0 4}$ & $\mathbf{1 1 , 3 0}$ & $\mathbf{1 1 , 6 3}$ & $\mathbf{1 4 , 0 2}$ & $\mathbf{1 7 , 5 5}$ \\
\hline
\end{tabular}

Usando esses dados para o cálculo direto do valor do capital próprio, tem-se que este monta em $t=0$ a $\$ 49,55$. A diferença entre esse valor e o calculado anteriormente é de $(\$ 8,70)$. E esse valor é explicado a seguir.

Aplicando-se a anatomia do valor da firma três ajustes são previstos: i) o ganho da dívida; ii) a variação de valor do ativo para o acionista e iii) a variação de valor do benefício fiscal para o acionista. 
Os ajustes são:

1) Ganho da Dívida em $\mathrm{t}=0 ; \mathrm{GD}_{0}=\sum_{\mathrm{t}=1}^{\mathrm{n}} \mathrm{Fcd}_{\mathrm{t}} \frac{\left(\mathrm{ke}_{\theta \mathrm{t}}-\mathrm{kd}_{\mathrm{t}}\right)}{\left(1+\mathrm{ke}_{\theta t}\right)^{\mathrm{t}}\left(1+\mathrm{kd}_{\mathrm{t}}\right)^{\mathrm{t}}}$. Fazendo os cálculos tem-se que $\mathrm{GD}_{0}=\$ 26,77$.

2) Variação do Valor do Ativo para o Acionista em $t=0$ :

$$
\Delta \mathrm{VA}_{0}=\sum_{\mathrm{t}=1}^{\mathrm{n}}\left(\mathrm{Fca}_{\mathrm{t}}^{\prime}\right)\left[\frac{\left(\mathrm{keu}_{\theta \mathrm{t}}-\mathrm{ke}_{\mathrm{ut}}\right)}{\left(1+\mathrm{ke}_{\theta t}\right)^{\mathrm{t}}\left(1+\mathrm{ke}_{\mathrm{ut}}\right)^{\mathrm{t}}}\right] .
$$

Fazendo-se os cálculos tem-se que $\Delta \mathrm{VA} 0=(\$ 31,05)$.

3) Variação do Valor do Benefício Fiscal Ativo para o Acionista em $t=0$ :

$$
\Delta \mathrm{BF}_{0}=\sum_{\mathrm{t}=1}^{\mathrm{n}}\left(\mathrm{Bf}_{\mathrm{t}}\right) \frac{\left(\mathrm{ke}_{\mathrm{ut}}-\mathrm{ke}_{\theta \mathrm{t}}\right)}{\left(1+\mathrm{ke}_{\mathrm{ut}}\right)^{\mathrm{t}}\left(1+\mathrm{ke}_{\theta \mathrm{t}}\right)^{\mathrm{t}}} .
$$

Fazendo-se os cálculos tem-se que $\Delta \mathrm{BF}_{0}=(\$ 4,41)$.

A soma dos ajustes dos itens i, ii e iii totaliza $(\$ 8,70)$. Portanto, a diferença entre os valores da avaliação 'ingênua' aplicando-se indistintamente MM é explicada pelo ganho da dívida de $\$ 26,77$, pela 'perda' de valor do ativo operacional de $\$ 31,05$ e pela 'perda' de valor do benefício fiscal de $\$ 4,41$.

Dessa forma, pode-se evidenciar a anatomia de valor da firma e do capital próprio em $\mathrm{t}=0$ da seguinte forma:

\begin{tabular}{|l|c|}
\hline \multicolumn{2}{|c|}{ ANATOMIA DE VALOR EM t=0 } \\
\hline Ativo & 102,20 \\
\hline Perda de valor ativo & $(31,05)$ \\
\hline Benefício fiscal & 16,05 \\
\hline Perda de valor do beneficio fiscal & $(4,41)$ \\
\hline Ganho da Dívida & 26,77 \\
\hline ATIVO TOTAL & $\mathbf{1 0 9 , 5 5}$ \\
\hline Dívida & 60,00 \\
\hline Patrimônio Líquido & 58,25 \\
\hline Perda de valor ativo & $(31,05)$ \\
\hline Perda de valor do beneficio fiscal & $(4,41)$ \\
\hline Ganho da Dívida & 26,77 \\
\hline PL total & 49,55 \\
\hline PASSIVO TOTAL & $\mathbf{1 0 9 , 5 5}$ \\
\hline
\end{tabular}

Com essa evidenciação no formato de balanço contábil, fica evidente o potencial de aumento da capacidade de análise dos componentes de valor da empresa e do capital próprio. No caso de implantação de novos projetos, com os mesmos riscos dos projetos 
já existentes ou com riscos distintos, a anatomia do valor proporciona a visualização dos efeitos de valor que esses novos investimentos terão sobre a empresa.

Caso a estrutura de capital seja alterada, como por exemplo através de recomposição e/ou troca de dívidas, também é possível verificar o efeito de valor dessa nova alavancagem proposta.

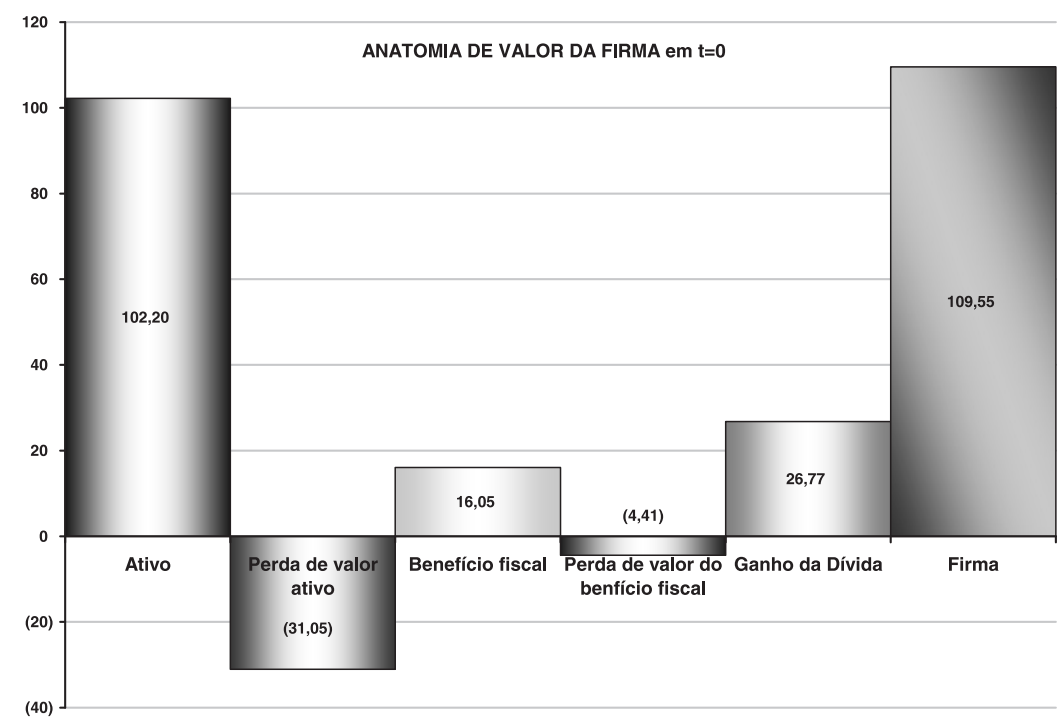

Além dos efeitos individuais, a anatomia do valor permite que os efeitos conjuntos dos novos projetos e do novo perfil da dívida sejam evidenciados.

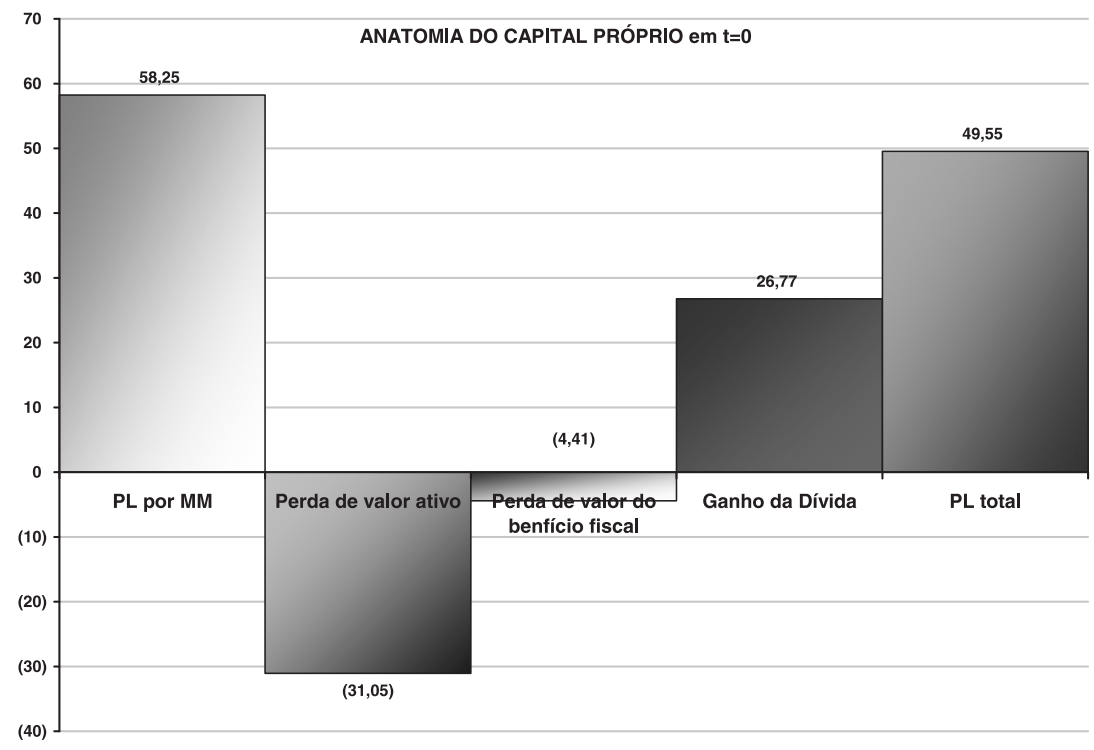


